\title{
El proceso de democratización de la gestión de servicios públicos esenciales de agua y saneamiento
}

\section{J. Esteban Castro*}

\section{Resumen}

Tras presentar las dimensiones conceptuales de la gestión democrática de los servicios públicos, en paralelo con el progresivo desarrollo de la ciudadanía o proceso de "ciudadanización", en este artículo se concretan dichas dimensiones en el análisis de los derechos de ciudadanía en el ámbito de los servicios de agua y saneamiento básico. A continuación, se muestra una perspectiva histórica de la gestión de tales servicios, identificándose las fases de la gestión "privatista", del "racionalismo administrativo" y de la actual tendencia "neo-privatizadora". Para concluir, el artículo alude a los desafíos que afronta el proceso de democratización de la gestión de los servicios públicos esenciales en el presente.

\section{Palabras clave}

Ciudadanía; Derechos Ciudadanos; Participación Ciudadana; Democratización; Servicios de Agua y Saneamiento

\section{Abstract: Democratization of the management of essential water and sanitation public services}

This paper presents the conceptual dimensions of the democratic management of public services in parallel with progressive development of citizenship, that is, citizen participation. Such dimensions are approached by analyzing citizens' rights in the context of basic water and sanitation services. Next, a historic perspective of the management of such services is provided, identifying the following stages: private management, "administrative rationalism" and the current "neoprivatization" trend. To conclude, the paper evokes the challenges faced by the current democratization of the management of essential public services.

\section{Key words}

Citizenship; Citizens' Rights; Citizen Participation; Democratization; Water and Sanitation Services 


\section{Introducción}

Este artículo aborda el tema de la democratización del gobierno y la gestión de los servicios de agua y saneamiento básico ${ }^{1}$ desde una perspectiva interdisciplinaria anclada en las ciencias sociales. Un presupuesto central del trabajo es que la necesidad de avanzar en el desarrollo de articulaciones inter y transdisciplinarias de cada vez mayor complejidad, especialmente entre las tecnociencias y las ciencias sociales, constituye uno de los desafíos más importantes que afronta la democratización de la gestión de los servicios públicos esenciales, y aquí se intenta hacer una contribución a dicho avance desde la sociología.

El principal argumento del artículo es que el desarrollo de los servicios modernos de agua y saneamiento básico en los países occidentales, un proceso relativamente reciente que data de fines del siglo dieciocho, está estrechamente relacionado con la evolución de las formas modernas de la democracia capitalista, notoriamente con las instituciones de la ciudadanía. Por esta razón examinamos con cierto detalle las relaciones entre los derechos de ciudadanía y el desarrollo de los servicios públicos esenciales, poniendo énfasis en los procesos que contribuyeron a la universalización del acceso a dichos servicios en las democracias capitalistas centrales durante el siglo veinte. El artículo también explora las etapas principales que se pueden discernir en las formas de gobernabilidad que han predominado en el ámbito de los servicios de agua y saneamiento básico urbanos en los países occidentales: desde sus orígenes centrados en los principios del privatismo económico y político predominantes a fines del siglo dieciocho, pasando por la institucionali-

\footnotetext{
${ }^{1}$ El concepto de "servicios de agua y saneamiento básico" en general se refiere primeramente a la provisión de agua apta para consumo humano y la recolección y tratamiento de residuos cloacales, pero también suele incluir otros servicios asociados como la gestión de aguas pluviales, la recolección y tratamiento de residuos sólidos o el control de vectores infecciosos. En general el artículo hará referencia a los dos prime-
} ros aspectos. zación y profesionalización de estos servicios y la ampliación del acceso a partir de la adopción de los criterios del racionalismo administrativo desde fines del siglo diecinueve, hasta las reformas neoprivatistas que se han venido implementando desde la década de 1980.

El objetivo central del trabajo es esclarecer las relaciones entre la gestión de los servicios de agua y saneamiento básico, tradicionalmente considerada una actividad fundamentalmente técnica, y el proceso de democratización de la sociedad, que tiene un carácter eminentemente social y político. Se parte de la premisa de la democratización de la gestión de estos servicios esenciales como un proceso de carácter social y político, que afronta una serie de desafíos cuya superación requiere una comprensión cada vez más precisa de las complejas relaciones entre los niveles sectorial y sistémico de dicho proceso. Este trabajo adopta una visión crítica de las formas dominantes de la democracia capitalista, que dan marco y estructura a las formas particulares de gestión de servicios públicos esenciales, ya que las mismas presentan severas limitaciones al proceso de democratización sustantiva de la sociedad, es decir, la democratización efectiva, no meramente formal o retórica, de las relaciones sociales. Pero, asimismo, el artículo examina objetivamente los avances logrados en el interior de la propia democracia capitalista, como la expansión del acceso a los servicios esenciales para la vida digna o la provisión de volúmenes adecuados de agua limpia y de condiciones sanitarias básicas, que han sido el producto de luchas sociales de largo plazo en la búsqueda de la emancipación humana y la democratización sustantiva. El hecho de que en décadas recientes algunos de estos avances hayan sido revertidos, por ejemplo a través de la introducción de reformas neo-privatistas en el gobierno y gestión de los servicios públicos, alerta sobre la fragilidad de 
los sistemas actuales de derechos ciudadanos y la necesidad de profundización del proceso de democratización, lo cual requiere en primer lugar la defensa y la recuperación de los derechos básicos que habían sido conquistados en etapas históricas anteriores. Algunos de los ejemplos utilizados en el artículo se refieren a la experiencia reciente de los países de América Latina, pues, desde la década de 1990, la región se convirtió en un campo experimental de las reformas neo-privatistas impulsadas a nivel internacional en relación con los servicios públicos esenciales, incluidos los servicios de agua y saneamiento. Tales ejemplos provienen de varios proyectos de investigación y redes académicas coordinados por el autor ${ }^{2}$, así como de la literatura especializada.

\section{Las dimensiones conceptuales de la gestión democrática}

Los servicios urbanos de agua y saneamiento modernos en red, tal como los conocemos actualmente en occidente, tienen una historia relativamente reciente que se remonta a fines del siglo dieciocho. No es casual la coincidencia con el origen de la democracia moderna occidental capitalista, ligada a la herencia de las revoluciones norteamericana y francesa de fines del mismo siglo. En realidad, el desarrollo de estos servicios ha estado fuertemente marcado por las luchas sociales que caracterizan al proceso democratizador, en función de lo cual, las dimensiones conceptuales que abordo aquí son: a) el progresivo desarrollo de la ciudadanía, a lo que denomino "ciudadanización" y b) las formas y principios de gobernabilidad que han caracterizado a la gestión de estos servicios.

Intentando ofrecer elementos para el estudio objetivo de las condiciones y mecanismos que pueden facilitar la democratización sustantiva, no

\footnotetext{
${ }^{2}$ Los proyectos PRINWASS (www.prinwass.org), GOBACIT
} (www.gobacit.org) y WATERLAT (www.waterlat.org). meramente formal, de la gestión de estos servicios, este trabajo explora las contradicciones intrínsecas del proceso de democratización occidental desde la perspectiva de sus implicaciones en la gestión de tales servicios. Cabe destacar que este artículo no considera que las formas concretas asumidas por el proceso prevaleciente de democratización en los países occidentales, es decir, las distintas versiones de la democracia liberal representativa que de un modo u otro conforman el modelo dominante a nivel internacional, constituyan la mejor forma de democratización a la que se pueda aspirar y mucho menos que constituyan la forma máxima de emancipación humana. Muy por el contrario, y reflexionando sobre las experiencias latinoamericanas, las formas concretas asumidas por los regímenes democráticos dominantes llevan a cuestionar profundamente el sentido mismo del concepto de democracia. Existe un profundo debate sobre este tema en América Latina, donde los regímenes democráticos existentes han sido conceptualizados, entre otros ejemplos, como "tutelados" (Walksman, 1989; Portales, 2000), "de baja intensidad" (Torres Rivas, 1989), “delegativos" (O'Donnell, 1994), y donde incluso la propia democracia como concepto ha sido considerada, en las ácidas palabras de Jorge Luis Borges, como una "superstición" (citado en Marín, 1996, p. 42). No es de extrañar, en este contexto, que incluso la profundización de los principios de la propia democracia liberal, y particularmente los principios de la ciudadanía, puedan asumir en la práctica el carácter de una propuesta que es percibida como demasiado radical, incluso extrema, por los sectores dominantes. Pero, además, este debate es tan pertinente en América Latina como en los países capitalistas centrales, donde se está experimentando una profunda crisis de legitimidad de los sistemas democráticos representativos.

En definitiva, se intenta demostrar en este artículo 
que tal debate tiene una importancia central para la gestión de los servicios de agua y saneamiento, un sector de actividad que tradicionalmente se relega a la dimensión técnico-administrativa, aislándolo artificialmente de los procesos culturales, socio-económicos y políticos que, sin embargo, estructuran, dan marco y hasta determinan la forma en que estos servicios son organizados y gestionados. En tal sentido, examinar las interrelaciones entre el desarrollo de estos servicios y el proceso de democratización nos permite alcanzar una comprensión más cabal y profunda de las condiciones sistémicas, los obstáculos y las oportunidades, que confronta la democratización de la gestión de unos servicios públicos esenciales.

\section{El progresivo desarrollo de la ciudadanía o proceso de "ciudadanización"}

La ciudadanía característica de la democracia liberal constituye como tal un fenómeno históricamente determinado, que a su vez asume una diversidad de formas en los distintos territorios, lo cual es consecuencia del desarrollo específico de culturas nacionales, regionales y locales que reflejan principios, valores e intereses materiales también diversos. Es decir, que, a pesar de ser un componente central de la democracia capitalista occidental, las formas específicas que asume la ciudadanía en los diversos territorios reflejan grandes diferencias y contradicciones, que discutimos en mayor detalle a continuación. Para ello, escogemos -entre los autores que han trabajado sobre el asunto- a Rogers Brubaker, en sus estudios sobre las diversas formas históricas del desarrollo de la ciudadanía en los casos de Alemania, Gran Bretaña, y Francia, y también a Benedict Anderson, en su reflexión sobre el carácter artificial, "imaginario", de las comunidades políticas (Brubaker, 1992; Anderson, 1983).

En primer lugar, debe entenderse que la ciudadanía en la democracia capitalista moderna es fun- damentalmente la identidad política que asumen los miembros de un estado nación, lo cual constituye una herencia de la Revolución Francesa (Delanty, 2000). Pero el aspecto que interesa examinar en este trabajo es el de la ciudadanía como relación social, o como he preferido denominarlo en esta sección, el proceso de "ciudadanización", es decir el desarrollo histórico de la ciudadanía como relación social. En esta perspectiva, este segundo aspecto de la ciudadanía tanto antecede a como también presupone el primero: por una parte la génesis histórica de los elementos característicos de la ciudadanía como relación social antecedieron a la formación de los modernos estados-nación, sin embargo, por otra parte, desde fines del siglo dieciocho el ejercicio de la ciudadanía ha presupuesto la pertenencia de los sujetos a una comunidad política garante de los derechos y deberes sobre los que se asientan dichas relaciones. Esta tensión entre los dos aspectos del proceso de ciudadanización tiende a profundizarse y cambiar de naturaleza en el contexto de las transformaciones experimentadas por el estado nación desde mediados del siglo veinte, con la expansión de comunidades políticas sub y supra nacionales. Entre otros ejemplos de estas transformaciones pueden mencionarse el reconocimiento de comunidades políticas regionales en el interior de los estados, como en el caso de las autonomías étnicas dentro del estado "pluri-nacional" de Bolivia reconocidas por la nueva Constitución de ese país aprobada en 2009, o la consolidación de ciertos derechos y deberes de ciudadanía a nivel transnacional como en el caso de la Comunidad Europea de naciones o, en forma más limitada, en el caso de los países del Mercosur (ver por ejemplo, Dávalos, 2005; Garcés et al., 2006; Giraudo, 2007; Líster y Pía, 2008). En este proceso, existen ciertos derechos y deberes que los ciudadanos y ciudadanas pueden ejercer con relativa independencia de su re- 
lación de identidad nacional: como por ejemplo, dentro de la Comunidad Europea, los ciudadanos y ciudadanas de cualquier país miembro pueden ejercer los derechos a la propiedad, a la residencia, al empleo o a la justicia en otros países miembros, e inclusive pueden apelar fallos de sus tribunales nacionales en los tribunales supranacionales de la Comunidad (ver, por ejemplo, Goldhaber, 2009). Este es un proceso muy dinámico y complejo que necesariamente implica profundas transformaciones en los contenidos y la extensión de la ciudadanía (ver por ejemplo Theory and Society, 1997).

Desde luego que este no es un proceso idílico y la ciudadanía, tanto en su carácter de identidad política como en el de relación social, encierra contradicciones fundamentales. En este sentido, en las democracias occidentales capitalistas la ciudadanía es una relación entre sujetos formalmente iguales y está circunscrita a un conjunto de derechos y obligaciones que regulan la propiedad, el acceso a la justicia, la participación política, y, en algunas sociedades, la distribución de ciertos bienes y servicios considerados esenciales como la educación, la salud o la vivienda y los servicios de agua y saneamiento básicos. Esta forma clásica de la ciudadanía, inspirada en la tradición liberal democrática, encarna una contradicción fundamental entre la igualdad formal y la desigualdad real, entre la igualdad uniforme presupuesta en los derechos ciudadanos y la gama de expresiones concretas que asume la desigualdad en el ejercicio real de los mismos. Esta tensión entre igualdad formal y desigualdad concreta caracteriza el desarrollo histórico del proceso de "ciudadanización", que ha experimentado un movimiento de expansión y extensión en los últimos dos siglos pero que también ha sufrido retrocesos recurrentes, como ocurre en los casos de suspensión o incluso cancelación de ciertos derechos ciudadanos durante períodos autoritarios o de retroceso democrático. Por ejemplo, la suspensión del habeas corpus, uno de los derechos civiles fundamentales de la democracia liberal, ha sido un hecho recurrente tanto en el marco de dictaduras cívico-militares como las que suspendieron la democracia electoral en países de América Latina y Europa durante décadas como crecientemente también en razón del avance de sectores autoritarios dentro de la propia democracia formal, como en el caso del secuestro y encarcelamiento sin derecho a juicio implementado sistemáticamente por el gobierno de Estados Unidos y sus aliados en el contexto de la "guerra contra el terror" impulsada por estos países desde 2001 (ver por ejemplo, Marín, 1996; Glenn, 2000; Fallon Jr. y Meltzer, 2007; Morrison, 2007). Otro ejemplo, que consideramos luego en mayor detalle dada su relevancia para nuestro tema, han sido las políticas neoliberales en relación a la gestión de bienes y servicios esenciales, como la educación, la salud y los servicios de agua y saneamiento básico. Estas políticas, implementadas globalmente desde la década de 1980, intentan cancelar la noción de que existen derechos sociales al acceso a tales bienes y servicios, un principio que las democracias capitalistas occidentales, al menos en Europa, habían consagrado durante el período de posguerra a partir de fines de la década de 1940 (ver, por ejemplo, Leys, 2001; Harvey, 2005).

Es importante recordar que fuera de Europa y Estados Unidos el proceso de "ciudadanización" fue transplantado, adoptado, adaptado o incluso impuesto por distintos mecanismos desde el siglo diecinueve, lo cual añade otro nivel de complejidad al análisis (Rokkan, 2009). Por ejemplo, desde mediados del siglo diecinueve se dio un proceso de implantación de los principios e instituciones de la democracia liberal en la mayoría de los países de América Latina, proceso que en gran medida tomó la forma de confrontaciones 
armadas y guerra civil (Escalante Gonzalbo, 1992; Roberts, 1995). En general, tal proceso de "ciudadanización” en América Latina estuvo limitado a comunidades políticas restringidas, excluyentes, frecuentemente compuestas por las elites gobernantes emergentes de la colonización europea y cerrado a las grandes mayorías. A pesar de los avances sustantivos experimentados en la mayoría de los países de la región desde el siglo diecinueve, todavía el ejercicio de los derechos de ciudadanía sigue siendo negado a amplios sectores de la población allí (Dagnino, 1994; Carvalho, 1995; Roberts, 1995; Fleury, 1997; Svampa, 2005; Sousa, 2006; Yamin, 2006). En realidad, puede decirse que esta dinámica de inclusión y exclusión es una característica central del proceso de "ciudadanización" en general (ver Cuadro 1).

Por una parte, la "ciudadanización" en la democracia capitalista es parte fundamental del proceso que garantiza la reproducción ampliada del sistema, ya que los principios fundantes de la ciudadanía en este contexto son el derecho a la propiedad privada y a la libertad individual para el intercambio mercantil de dicha propiedad. Por otra parte, sin embargo, en cierto sentido las instituciones de la ciudadanía y del sistema capitalista entran también en contradicción, "están en guerra", como indicara T.H. Marshall, ya que la expansión y profundización del contenido, alcance y ejercicio de la ciudadanía son constitutivas de las luchas emancipatorias que caracterizan al sistema (Marshall, 1963). De este modo, la ciudadanía provee la base de igualdad formal que legitima el sistema de desigualdad real, pero al mismo tiempo provee las condiciones que potencialmente pueden dar lugar a un proceso de igualación creciente de los desiguales. Basten como unos pocos ejemplos los casos clásicos de la extensión de los derechos a la propiedad y al voto a las mujeres, derechos que hasta comienzos del siglo veinte constituían un monopolio masculino y el reconocimiento de los derechos de los trabajadores a una jornada de 8 horas y a un salario mínimo, o más recientemente la reivindicación de los derechos lingüísticos de las comunidades indígenas de América Latina que algunos países como Bolivia y Ecuador han comenzado a formalizar en sus cartas constitucionales (Dávalos, 2005; Giraudo, 2007; Ordóñez Cifuentes, 2003). Indudablemente, la extensión del contenido de los derechos, la expansión de la comunidad beneficiaria de los mismos, y la profundización de su ejercicio real y no meramente formal, constituyen avances en el proceso de democratización de la sociedad resultantes de luchas sociales recurrentes.

Desde otro ángulo, el desarrollo de la ciudadanía está íntimamente relacionado con el proceso de mercantilización, es decir, con el proceso mediante el cual las relaciones sociales tienden a transformarse en relaciones mercantiles. La mercantilización creciente de los elementos de la naturaleza, incluyendo el agua y los servicios basados en o derivados del agua, es parte componente de dicho proceso. Este es otro aspecto importante de las contradicciones que caracterizan al desarrollo del gobierno y la gestión democrática de los servicios de agua y saneamiento. Como discutiremos luego en mayor detalle, el desarrollo de los primeros sistemas urbanos de agua en los países capitalistas centrales, principalmente en Inglaterra y Francia, tuvo como principio fundante la noción de que el servicio de agua corriente en las viviendas era una mercancía cuyo acceso se limitaba a quienes pudieran pagarla. Es decir, el punto de partida del desarrollo de lo que hoy consideramos un servicio esencial para la vida civilizada no fue el de satisfacer una necesidad común a todos los habitantes sino más bien el de producir una mercancía, es decir, un objeto de apropiación privada, orientado a producir una ganancia, y dirigida sólo a quien tenía la capacidad económica de 
comprarla, el cliente privado solvente o consumidor. Necesariamente, en esa etapa temprana de la historia de estos servicios, esa categoría social emergente, el cliente privado del agua-mercancía, correspondía a un sector muy reducido de la población, el mismo que también constituía la ciudadanía propiamente dicha, es decir, aquella parte de la población que accedía al ejercicio pleno de los derechos ciudadanos. Evidentemente, esta relación íntima entre los procesos de "ciudadanización" y mercantilización no es exclusiva del ámbito de los servicios de agua y saneamiento sino que más bien caracteriza el desarrollo de la democracia capitalista en sus diversos aspectos, incluyendo la esfera del acceso a los bienes y servicios de consumo colectivo (ver, por ejemplo, Kroen, 2004; Soper y Trentmann, 2008).

\section{Los derechos de ciudadanía, el agua y los servicios de agua y saneamiento básico}

La existencia o no de un derecho al acceso al agua limpia para consumo humano y a los servicios básicos de drenaje sanitario, recolección y tratamiento de residuos y otras necesidades esenciales para la vida digna es objeto de un debate inconcluso (véase, por ejemplo, Esch et al., 2006). Aquí se aborda este tema desde dos ángulos: por una parte, examinamos brevemente la emergencia de los derechos y deberes de la ciudadanía y su relación con estos servicios esenciales $y$, por otra parte, se asume la posición de que, en efecto, el acceso a estos servicios constituye un derecho fundamental (ver Cuadro 2 al final de esta sección). Los derechos de ciudadanía clásicos desarrollados en los países occidentales han sido categorizados en "civiles", "políticos" y "sociales", a los cuales se han ido incorporando otras dimensiones en el curso del proceso de "ciudadanización", como por ejemplo los derechos trans-específicos (el reconocimiento de otras especies, de la propia naturaleza, e inclusi- ve de entes artificiales como sujetos de derechos) $y$ trans-generacionales (el reconocimiento de las generaciones futuras como sujetos de derechos). Los derechos civiles de ciudadanía son básicamente el derecho a la propiedad y a la justicia, es decir los derechos individuales fundamentales en el contexto de la democracia capitalista. Los derechos políticos, que se consolidan a partir del siglo dieciocho tienen que ver fundamentalmente con el derecho también individual a elegir o ser elegido/a para participar en el gobierno. Los derechos_sociales, por su parte, consisten en el reconocimiento de que ciertos bienes y servicios esenciales para la vida digna deben estar disponibles a todos los miembros de la comunidad con independencia de su posición en el mercado, es decir, con independencia de su capacidad de pago. Existe una amplia controversia en torno a los derechos sociales: para la tradición liberal individualista tales derechos no existen ya que la misma restringe los derechos de ciudadanía solamente a los derechos civiles y políticos. Es decir, en esta tradición político-intelectual, bienes y servicios esenciales como los servicios de agua y saneamiento básico no tienen el estatus de derechos ciudadanos ya que se los considera bienes económicos privados que deben ser adquiridos individualmente en el mercado como cualquier otro tipo de bien o servicio, es decir, como una mercancía. Este ha sido y sigue siendo un debate de importancia central para la gestión democrática de los servicios públicos esenciales.

En las últimas décadas, el debate sobre los derechos y deberes de la ciudadanía ha avanzado incorporando nuevas dimensiones, particularmente a partir de la creciente toma de conciencia a nivel internacional sobre la insustentabilidad del modelo de desarrollo dominante, especialmente en relación a su impacto sobre el ambiente y los procesos ecológicos. La profundización de este debate ha llevado a la ampliación del contenido 
de los derechos y deberes ciudadanos, de modo que adicionalmente a los derechos civiles, políticos y sociales se ha incorporado una serie de derechos de ciudadanía ampliados que incluyen el derecho a vivir en un ambiente limpio (libre de la contaminación de los ecosistemas acuáticos, del suelo o del aire), pero también el derecho del resto de los seres vivos y de la propia naturaleza a la preservación de las condiciones que posibilitan la vida en el planeta, y el derecho de las futuras generaciones a disfrutar de dichas condiciones (ver Figura 1).

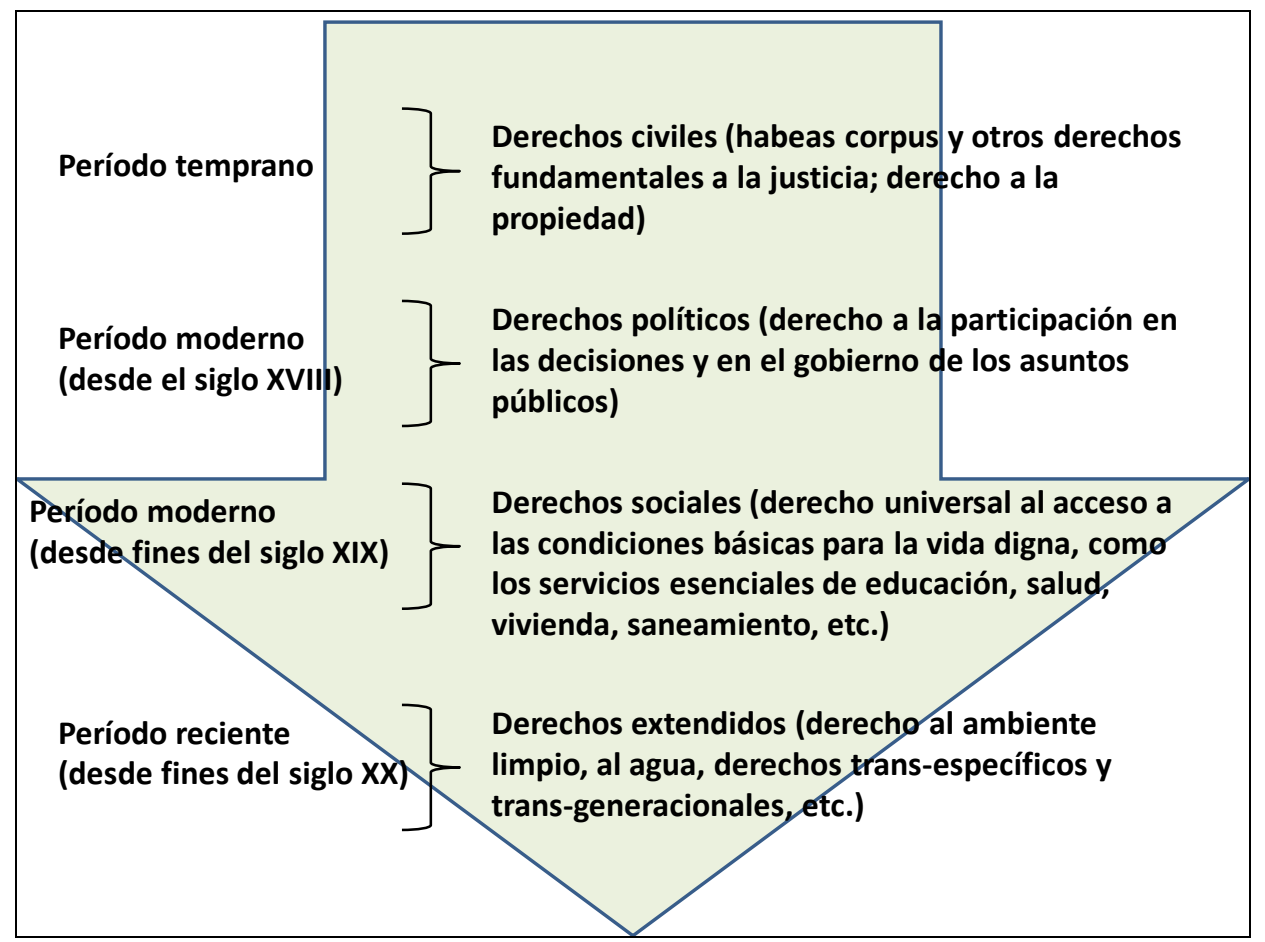

Figura 1. La evolución del proceso de “ciudadanización” liberal democrático. Fuente: elaboración propia.

No existe acuerdo respecto a estos derechos extendidos o ampliados de la ciudadanía, y desde distintos ámbitos del espectro político se discute la validez y utilidad de los mismos. Por ejemplo, para algunos actores involucrados directamente con el desarrollo de la infraestructura de servicios el debate de los "derechos" es una discusión artificial, de poca utilidad, que no contribuye a las tareas inmediatas de extender el acceso a sistemas de agua y saneamiento a las poblaciones no atendidas. En este sentido, en un debate reciente que tuvo lugar en la Universidad de Sussex en Inglaterra ${ }^{3}$, actores comprometidos con la tarea de extender la infraestructura de servicios en

\footnotetext{
3 "Simposio sobre el Agua" llevado a cabo por el Institute of Development Studies (IDS) de la Universidad de Sussex el 2 y 3 de noviembre de 2009.
}

países pobres plantearon que el debate del derecho al agua carece de sentido y tiene poca relación con la realidad que ellos deben confrontar en el terreno. Los técnicos que expresaban esta opinión consideran que la tarea que ellos realizan como ingenieros civiles encargados de la construcción de obras de agua y saneamiento es "neutra" en términos políticos y ven con desconfianza y escepticismo la politización del debate sobre el acceso a estos servicios, un debate que se da precisamente en torno a la noción de que existe un derecho a los mismos. Por otra parte, las grandes empresas transnacionales que controlan el mercado privado de los servicios de agua y saneamiento a escala global también han comenzado a utilizar la noción del "derecho humano al agua" abiertamente declarando su apoyo y dispo- 
nibilidad para contribuir a su implementación práctica (véase, por ejemplo, Labre, 2007; Veolia, 2007). Lamentablemente, estos actores no profundizan en las contradicciones existentes entre la noción de derecho humano al agua y el proceso de mercantilización de los servicios urbanos esenciales que sus empresas encarnan en la práctica. Antes de examinar estas contradicciones nos detendremos brevemente aquí para considerar algunas vinculaciones conceptuales entre ambos procesos.

\section{Derechos civiles}

En primer lugar, cuando consideramos los derechos civiles de ciudadanía, es decir, fundamentalmente el derecho a la propiedad y a la justicia, pueden establecerse conexiones importantes con los servicios de agua y saneamiento. Indudablemente el elemento clave en el funcionamiento de estos servicios es el agua, o más precisamente los ecosistemas acuáticos, aunque con frecuencia, en el lenguaje técnico, se tiende a reducir el agua a su dimensión económica, el agua como "recurso". Pero incluso en una concepción limitada de lo que es el agua que la reduzca a su dimensión de "recurso" económico, es posible hacer observable su relación con los derechos ciudadanos, lo cual nos lleva a desarrollar una serie de preguntas. Si el derecho básico de la ciudadanía en la democracia capitalista es la propiedad, ¿quién tiene la propiedad del agua? Esta pregunta tiene una respuesta más sencilla en el caso del agua en los sectores rurales, donde en general la propiedad de la misma suele estar vinculada a la propiedad de la tierra. Pero en relación a los servicios de agua y saneamiento básico en medios urbanos la pregunta asume otro carácter, dado que la propiedad del agua en el caso de los aglomerados humanos plantea un problema diferente. Formalmente los derechos de propiedad sobre el agua, con algunas excepciones, como es el caso de Chile, están en manos del estado, el que a su vez extiende derechos de abstracción y de descarga de aguas residuales a las empresas que se encargan del suministro de estos servicios. Dejando de lado por un momento la dimensión legal, que, pese a su fundamental importancia, sólo representa un aspecto del problema, vale la pena repetir la pregunta: ¿Quién tiene la propiedad del agua, en el sentido de derecho fundamental de la ciudadanía en una democracia capitalista, en relación a los servicios de agua y saneamiento básico? ¿Tienen los ciudadanos y ciudadanas individuales un derecho de propiedad sobre el agua en la que se basan estos servicios? ¿Si lo tienen, de qué forma ejercen dicho derecho? En la práctica la respuesta genérica a esta pregunta sería que el estado ejerce ese derecho en nombre de los ciudadanos y ciudadanas individuales, ya que el estado detenta los derechos de propiedad sobre el agua en última instancia. $\mathrm{O}$, en otras palabras, los ciudadanos y ciudadanas ejercen su derecho indirectamente, por mediación del estado. De este modo, cuando el estado otorga derechos de abstracción de agua limpia o derechos de descarga de aguas residuales a una empresa de servicios, lo está haciendo en representación de los ciudadanos y ciudadanas, que son quienes detentan el derecho ciudadano sobre los ecosistemas acuáticos en cuestión. Es probable que este argumento pueda resultarle esotérico a algunos lectores, porque en la práctica la relación entre la ciudadanía y los ecosistemas acuáticos, y con el territorio en términos más generales, suele ser invisible, inobservable, ya que los ciudadanos y ciudadanas comunes han sido históricamente excluidos del control efectivo de la propiedad, gobierno y gestión de bienes como el agua en las ciudades.

Un problema importante que surge de esta aplicación del concepto de derecho civil de ciudadanía en relación al agua, y en particular el derecho al agua como propiedad privada, es que en la 
práctica la formación de derechos privados de propiedad sobre el agua es un proceso de muy largo plazo, que ha asumido una diversidad de formas en los distintos territorios, y es un proceso fundamentalmente parcial, incompleto, inconcluso. El proceso de expansión de relaciones de propiedad y producción capitalista ha experimentado avances significativos en casi todas las esferas de la vida a escala planetaria, y sin embargo el caso del agua sigue siendo todavía un espacio por conquistar ${ }^{4}$. Puede afirmarse con cierta seguridad que aún a comienzos del siglo veintiuno una gran parte del agua utilizada a nivel internacional no ha sido convertida en propiedad privada y más bien está sujeta a diversas formas de propiedad y tenencia que incluyen formas comunitarias, públicas, etc. Las políticas neo-privatistas implementadas desde la década de 1980 han intentado acelerar este proceso de privatización de la propiedad del agua, pero esas políticas han encontrado enormes obstáculos y retrocesos y puede decirse que existen muy pocos ejemplos a nivel internacional en los que se haya logrado el objetivo de privatizar la propiedad del agua.

En conexión con esto, otro aspecto relevante que emerge de este tratamiento de la relación entre los derechos civiles de la ciudadanía y el agua es la contradicción que se produce a partir de la introducción de las instituciones y principios de la democracia liberal, como es la ciudadanía, en contextos en los cuales pre-existen formas de propiedad y gestión del agua fundados en principios e instituciones diferentes, frecuentemente antagónicos a los principios e instituciones capitalistas. En este caso, la introducción de derechos ciudadanos de cuño occidental, como el de la propiedad privada en la gestión del agua y sus

\footnotetext{
${ }^{4}$ Es interesante destacar que el avance lento de las instituciones de la propiedad privada sobre bienes como el agua fue destacado por North y Thomas en su famoso trabajo de historia económica en el que relacionaban el éxito del capitalismo occidental precisamente en el surgimiento de dichas instituciones (North y Thomas, 1973).
}

servicios asociados, conduce frecuentemente a profundas confrontaciones, muchas veces irresueltas o posiblemente irresolubles. Por ejemplo, este es uno de los ejes en el debate actual sobre la gestión del agua en Bolivia, donde algunos actores advierten que la introducción de derechos ciudadanos liberal democráticos en la gestión del agua representa la expropiación de los derechos de agua pre-existentes, fundados en principios e instituciones indígenas caracterizados por una diversidad de formas de derechos de propiedad colectivos. La misma noción de un estado garante de los derechos de propiedad de agua privados es vista por estos actores como una amenaza a la gestión democrática efectiva del agua y sus servicios en el contexto de sociedades altamente segregadas como la boliviana (véase por ejemplo, Crespo, 2010; también Boelens, 2008, sobre las sociedades andinas en general; ver también Salzman, 2005). Este ejemplo nos ilustra una cuestión fundamental del proceso de democratización: la evidencia sugiere que la interacción entre el proceso de ciudadanización liberal democrático dominante y las formas pre y co-existentes de derechos y obligaciones puede potencialmente contribuir a la emergencia de nuevas relaciones sociales en torno a la propiedad, gestión y gobierno del agua y de sus servicios esenciales.

\section{Derechos políticos}

La segunda dimensión de los derechos básicos de ciudadanía concierne los derechos políticos. En este caso, en relación al agua y a los servicios básicos de agua y saneamiento puede plantearse una serie de cuestiones que van al corazón del problema de la gestión democrática. Los derechos políticos tienen que ver con la participación de los ciudadanos y las ciudadanas en el ejercicio del poder, en el gobierno de los asuntos comunes, ya sea mediante su derecho a elegir a quienes gobiernan o a ser elegidos para participar directamente en el gobierno. En la práctica co- 
rriente de los sistemas democráticos vigentes para las grandes mayorías el ejercicio de los derechos políticos tiende a limitarse a la participación electoral en la que los ciudadanos y las ciudadanas eligen a sus gobernantes y por lo tanto el ejercicio de los derechos políticos más allá del momento electoral es excepcional. En el caso de la gestión del ambiente, incluyendo el agua y los servicios de infraestructura básica, los ejemplos de la ausencia del ejercicio de los derechos políticos son abundantes. Por ejemplo, en la Cumbre de la Tierra de las Naciones Unidas celebrada en Río de Janeiro en 1992 la mayoría de los gobiernos se comprometió a establecer los mecanismos jurídicos y administrativos que posibiliten a los ciudadanos y ciudadanas el ejercicio de sus derechos ambientales. El Principio 10 adoptado en la cumbre estipula que:

"El mejor modo de tratar las cuestiones ambientales es con la participación de todos los ciudadanos interesados, en el nivel que corresponda. En el plano nacional, toda persona deberá tener acceso adecuado a la información sobre el medio ambiente de que dispongan las autoridades públicas, incluida la información sobre los materiales y las actividades que encierran peligro en sus comunidades, así como la oportunidad de participar en los procesos de adopción de decisiones. Los Estados deberán facilitar y fomentar la sensibilización y la participación de la población poniendo la información a disposición de todos. Deberá proporcionarse acceso efectivo a los procedimientos judiciales y administrativos, entre éstos el resarcimiento de daños y los recursos pertinentes" (ONU, 1992).

Sin embargo, a pesar de las loables intenciones de la Declaración de Río y de los avances significativos que han sido logrados en el plano legalformal en muchos países, en la práctica los ciudadanos y ciudadanas comunes siguen asistiendo más como espectadores que como participantes con derechos en la gestión ambiental, incluyendo la gestión del agua y sus servicios. Un ejemplo notorio ha sido la profundización y aceleración de la implementación de las políticas neoprivatistas a nivel internacional desde la década de 1990, precisamente la misma década en la que se aprobó la declaración de Río. En la gran mayoría de los países la implementación de estas políticas, que han incluido no solamente la privatización del agua y sus servicios, sino también un amplio rango de iniciativas con consecuencias directas sobre el derecho a un ambiente limpio y seguro. Por ejemplo, volviendo al caso de los países de América Latina, desde comienzos de la década de 1990 se ha asistido al avance vertiginoso de procesos como la introducción masiva de cultivos genéticamente modificados, el impulso directo o indirecto a la deforestación, la radicación de industrias contaminantes que emigran de los países centrales donde la regulación es más estricta, la expansión de monocultivos promovida por políticas de fomento a la exportación masiva de materias primas agrícolas y la consecuente reducción de la biodiversidad, el uso incontrolado de agroquímicos que envenenan las tierras y las aguas y están afectando la salud de millones de personas, la continuidad de grandes obras de infraestructura con impactos sociales y ambientales altamente negativos, la expansión sin precedentes de la minería a cielo abierto con el uso de substancias como el cianuro inclusive en regiones de alta fragilidad ecológica, entre otras muchas políticas que se han venido implementando en gran medida de espaldas a la opinión e intereses de las comunidades afectadas y de la mayoría de los ciudadanos y ciudadanas (ver entre otros: Bebbington et al., 2008; Kuecker, 2007; Nelson y Robertson, 2008; Newell, 2009; Rulli, 2009; Urkidi Azkarraga, 2010; van Dijck y den Haak, 2007). En los pocos casos en que los gobiernos han dado a sus ciudadanos y ciudadanas la oportunidad de participar en forma decisiva en las decisiones se ha manifestado un rechazo contundente a estas 
iniciativas, pero en la mayoría de los casos se ha optado por la implementación de dichas políticas en formas que ignoran si no directamente violan los derechos políticos de los ciudadanos y ciudadanas. Las privatizaciones masivas realizadas por los gobiernos de Carlos Menem en Argentina (1989-1999), Gonzalo Sánchez de Losada (19931997) y Hugo Banzer (1997-2001) en Bolivia y Fernando Henrique Cardoso (1995-2002) en Brasil son ejemplos notables de esta situación, pero lamentablemente el ejercicio de los derechos políticos en relación al ambiente y a los servicios esenciales sigue siendo postergado y hasta negado incluso en el contexto de gobiernos que nominalmente se consideran progresistas o de izquierda.

Un determinante fundamental en el mantenimiento de las situaciones que impiden a la mayoría de la población el ejercicio de sus derechos políticos en forma substantiva, o por lo menos que limitan severamente dicho ejercicio, es la reproducción de desigualdades sociales estructurales, las cuales son notoriamente extremas en América Latina. Históricamente el ejercicio substantivo de los derechos políticos en la región ha sido restringido a ciertas fracciones de clase dominantes, y la rápida ampliación de la participación de la población en el ejercicio de estos derechos desde mediados del siglo veinte fue violentamente restringida mediante la instalación de dictaduras cívicomilitares que han dejado una huella profunda en las sociedades del continente. En realidad, como lo demuestran los acontecimientos recientes en Bolivia (2008), Honduras (2009) y Paraguay (2009), pero también en menor medida en otros países, la cancelación mediante el recurso a golpes de estado de los de por sí muy limitados derechos políticos en vigor en América Latina es un mecanismo latente y que cuenta con el apoyo de importantes sectores de la población. Pero inclusive en el marco institucional democrático vigente, los derechos políticos de los ciudadanos y ciudadanas se ven limitados en gran medida al ejercicio del voto en los períodos electorales, y cualquier intento de ampliación de su ejercicio debe enfrentar la oposición férrea de los sectores que tradicionalmente han detentado el poder. Estas severas limitaciones de la ciudadanía política en América Latina están estrechamente relacionadas con el carácter restringido, tutelado, de baja intensidad, de la democracia en estos países. No es de extrañar que en un contexto social en el que los derechos políticos en general se encuentran altamente restringidos también su ejercicio en relación a la gestión de los servicios públicos esenciales se encuentre severamente afectado.

\section{Derechos sociales}

La tercera dimensión de la ciudadanía en su forma liberal democrática es la de los derechos sociales. La noción de derechos sociales de ciudadanía, encarnada en las instituciones del "Estado de Bienestar" desarrolladas en la Europa de la segunda posguerra y adoptadas en distintas formas en otros países, parte del reconocimiento de que el acceso a ciertos bienes y servicios esenciales para la sobrevivencia y la vida digna debe tener carácter universal y debe ser independiente de la posición de los individuos y las familias en el mercado, o, en términos más sencillos, debe ser independiente de la capacidad de pago de las personas. Como lo expresara T.H. Marshall (1963), la noción de derechos sociales asume que todos los miembros de una comunidad política deben tener acceso irrestricto al "patrimonio común" que ha sido desarrollado por la sociedad en cuestión, específicamente en términos de ciertas cuestiones fundamentales como la educación básica, el cuidado de la salud, y las condiciones materiales de vida esenciales como la vivienda y los servicios de agua y saneamiento. Ahora bien, esta noción de derechos sociales ha sido siempre rechazada por algunas tradiciones intelectuales y 
políticas, particularmente por las tradiciones liberal individualista y algunas fracciones neoconservadoras, para las cuales la noción de derecho social constituye más bien un obstáculo al ejercicio de la ciudadanía. Para estos actores los derechos de ciudadanía se reducen a los derechos civiles y políticos, mientras que los así llamados derechos sociales constituyen un atentado a la libertad individual y un obstáculo al cumplimiento de los deberes de la ciudadanía ya que, de acuerdo a estos actores, la provisión pública de bienes y servicios sería una fuente de corrupción del sentido de responsabilidad de los individuos (ver por ejemplo Murray, 1984; Mead, 1986; véase también la crítica de King, 1988). Otras tradiciones ubicadas más a la izquierda en el espectro político también han dirigido severas críticas a los derechos sociales de ciudadanía, o más precisamente a sus instituciones como el "Estado de Bienestar", ya que las mismas han sido utilizadas para legitimar el sistema capitalista de explotación mediante políticas redistributivas que apenas apuntan a amortiguar el impacto de las desigualdades estructurales del sistema sin cuestionar sus fundamentos. De este modo, en esta perspectiva las políticas asociadas con los derechos sociales de ciudadanía representan una contribución al mantenimiento de la explotación de clase más que una posibilidad emancipatoria para las mayorías trabajadoras (ver por ejemplo los trabajos ya clásicos de Preteceille, 1974, Decaillot et al., 1977; Lojkine, 1979, entre otros; más recientemente, Kouvélakis, 2005).

En relación a la experiencia de América Latina, el debate sobre los derechos sociales de ciudadanía ilumina una serie de contradicciones que caracterizan al desarrollo de las comunidades políticas en la región. Por una parte, en sentido estricto y con pocas excepciones los derechos sociales en América Latina no llegaron a consolidarse en el tipo de instituciones que se desarrollaron en Eu- ropa como parte del "Estado de Bienestar". Si bien algunos países desarrollaron sistemas eficientes y de carácter universal para la provisión de ciertos servicios, como la educación básica o la atención de la salud, en la gran mayoría de los casos estos desarrollos han sido muy limitados en su alcance, con la excepción clásica de la Cuba revolucionaria y, en algunas áreas y durante ciertos períodos históricos, de países como Argentina, Chile, Costa Rica o Uruguay. Por otra parte, como ha señalado Roberts, en algunos aspectos el desarrollo de los derechos sociales de ciudadanía en América Latina ha precedido al desarrollo de los derechos civiles y políticos, lo cual constituye un proceso inverso al que tuvo lugar en las democracias capitalistas centrales en las cuales los derechos sociales fueron los últimos en consolidarse (Roberts, 1995).

\section{Los derechos extendidos o ampliados}

Los derechos extendidos de la ciudadanía son el resultado de procesos que han tenido lugar principalmente desde la década de 1960. Tanto por su carácter reciente como por su naturaleza y contenido estos derechos también resultan ser altamente controvertidos y han sido sujetos a fuertes críticas (ver Cuadro 3). En primer lugar podemos indicar la extensión de los derechos y deberes de la ciudadanía a una serie de ámbitos anteriormente no contemplados en forma directa o explícita, como por ejemplo los derechos sexuales, el derecho al ambiente, los derechos de los niños, los derechos étnicos, o más recientemente inclusive el "derecho al agua", que ha desatado un amplio debate (ver, por ejemplo, Esch et al., 2006). En general estos derechos y deberes han sido incluidos en declaraciones internacionales, muchos de ellos han sido sancionados en las constituciones de los países e inclusive han sido incorporados en la legislación, pese a lo cual la evidencia sugiere que el progreso ha sido más 
retórico que real en la mayoría de los casos. Esta es la base de las críticas más severas, que desde distintos ámbitos del espectro político apuntan a la falta de concreción de estos derechos ampliados y, especialmente, a las dificultades inherentes a su implementación práctica. En segundo lugar, se ha dado un proceso de extensión espaciotemporal del sujeto de la ciudadanía. Por una parte, algunos derechos han sido atribuidos a entes y seres no humanos lo cuales, según algunas posiciones, deberían ser aceptados como sujetos de derechos ciudadanos. Distintos intentos por extender los derechos de ciudadanía más allá de la especie humana buscan convertir a los animales, a la naturaleza, e inclusive a entes artificiales como los robots en sujetos de derechos ciudadanos (ver por ejemplo Goodin et al., 1997; Gray, 2001; IPSOS-MORI, 2006). Por otra parte, en debates como el de la sustentabilidad ambiental se ha dado una convergencia de los argumentos a favor de formas trans-específicas de ciudadanía con aquellos que proponen la extensión trans-generacional de los derechos. En efecto, en la perspectiva de la sustentabilidad se encuentra implícito el reconocimiento del derecho de las generaciones aún no nacidas a las condiciones básicas de vida, que requieren la preservación de la base natural de la vida y del ambiente (ver, entre otros, Steenbergen, 1994; Newby, 1996).

En perspectiva histórica, el proceso de extensión y profundización de los derechos y deberes ciudadanos resultante de diversas luchas emancipatorias ha ido transformando el significado de la ciudadanía, y muy particularmente en su carácter de relación social. Simultáneamente, es necesario evitar que los avances que representa este proceso en el plano legal-formal obstaculicen nuestra comprensión de la complejidad del mismo, ya que dichos avances van frecuentemente acompañados por la profundización de ciertas formas tradicionales de exclusión y desigualdad social y por la emergencia de nuevas formas (Tilly, 2003). Por otra parte, el proceso de ciudadanización conlleva el potencial de transformar el carácter de la ciudadanía y dar lugar a nuevas formas de relación social que eventualmente superen las contradicciones de los sistemas de ciudadanía prevalecientes. Estos sistemas están fundados en última instancia en los principios de la democracia liberal capitalista, los cuales se sustentan en el proceso real de producción y reproducción de desigualdades estructurales que son incompatibles con la democracia substantiva.

\section{La participación social y la esfera pública}

La participación es un componente central de los conceptos de ciudadanía y de gestión democrática. En el desarrollo histórico de la ciudadanía como relación social, puede decirse que aquello que en los debates contemporáneos se denomina la "participación ciudadana" tiene su origen en las luchas sociales por la expansión de los derechos de ciudadanía a sectores cada vez más amplios de la población, y en particular por la expansión de los derechos políticos que comienza a consolidarse en Europa durante el siglo diecinueve. En este sentido, la participación ciudadana está estrechamente vinculada con el desarrollo de la esfera de lo público, un proceso que también ha estado sujeto a las particularidades históricas de los distintos territorios y que ha tomado dimensiones diferentes en función de la diversidad de tradiciones y culturas políticas. Por ejemplo, mientras que la tradición liberal de la democracia representativa convencionalmente restringe la participación en las decisiones de la esfera pública a los políticos profesionales y a los expertos, otras tradiciones rechazan esta definición restringida y elitista y proponen diversas alternativas incluyendo la participación directa de los ciudadanos y las ciudadanas en las decisiones (véase, por ejemplo, Robbins, 1995; Ferree et al., 2002; ver Cuadro 4). Esto ilustra el hecho de que conceptos 
como "democracia", "ciudadanía" o "participación" son conceptos de alta generalidad y vaguedad, que requieren incorporar la dimensión históricosocial, el contexto, para dar mayor precisión a su significado. Este punto tiene gran relevancia para el debate sobre la participación y el control social en la gestión democrática de los servicios públicos esenciales.

\begin{tabular}{|c|c|c|c|}
\hline \multirow[t]{2}{*}{ Tradiciones políticas } & \multicolumn{3}{|c|}{ Criterios de participación social } \\
\hline & ¿Quién participa? & $\begin{array}{l}\text { ¿En qué tipo de } \\
\text { proceso? }\end{array}$ & Resultado \\
\hline $\begin{array}{l}\text { Liberal } \\
\text { representativa }\end{array}$ & $\begin{array}{l}\text { La elite política } \\
\text { profesional; los } \\
\text { expertos }\end{array}$ & $\begin{array}{l}\text { Libre mercado de } \\
\text { ideas }\end{array}$ & $\begin{array}{l}\text { Restricción } \\
\text { (sistémica) de la } \\
\text { participación }\end{array}$ \\
\hline Liberal participativa & $\begin{array}{l}\text { Posibilidad de } \\
\text { participación popular } \\
\text { restringida }\end{array}$ & Empoderamiento & $\begin{array}{l}\text { Evitar la restricción } \\
\text { (sistémica) de la } \\
\text { participación }\end{array}$ \\
\hline Discursiva & Inclusión popular & Deliberativo & $\begin{array}{l}\text { Evitar la restricción } \\
\text { prematura, no } \\
\text { consensuada }\end{array}$ \\
\hline Construccionista & Inclusión popular & $\begin{array}{l}\text { Empoderamiento } \\
+ \\
\text { Reconocimiento }\end{array}$ & $\begin{array}{l}\text { Evitar la restricción } \\
\text { excluyente } \\
\text { Expande la } \\
\text { comunidad política }\end{array}$ \\
\hline
\end{tabular}

Cuadro 1. Esfera pública y participación social en tradiciones políticas rivales. Fuente: Adaptado de Ferree et. al., 2002.

Aproximadamente desde la década de 1980 el concepto de participación pasó a cobrar gran importancia en los debates sobre las políticas públicas en el área de servicios esenciales como la atención de la salud, el acceso a la vivienda, la educación o el agua y el saneamiento básico. Nuevamente la referencia a la experiencia latinoamericana permite ejemplificar estos argumentos. Por una parte, la retirada de las dictaduras cívico-militares y el retorno de la democracia electoral a los países de la región permitieron la apertura de espacios más amplios para la participación efectiva de la población en la vida política. Por otra parte, desde la década de 1970 se registró en muchos países de la región una creciente movilización social en torno a la búsqueda de mejoras en las condiciones materiales de vida, especialmente en las zonas urbanas y peri- urbanas, un proceso en el que la lucha por el acceso a los servicios de agua y el drenaje sanitario pasó a jugar un papel muy importante (Castro, 2006). En este sentido, puede decirse que en este contexto de recuperación de los espacios de la democracia formal y de creciente movilización social por la mejora de las condiciones vitales el concepto de participación social fue tomando contenidos concretos surgidos de dichas experiencias. En algunos casos, notoriamente en Brasil, el proceso incluso llegó a promover iniciativas de políticas públicas fundadas en el principio de la participación ciudadana efectiva y la democracia directa, como es el caso del presupuesto participativo (Dutra y Benevides, 2001; Fedozzi, 2001). Ahora bien, como en todo proceso social y político, las experiencias tienden a seguir desarrollos determinados por múltiples circunstancias y diná- 
micas, cuyos resultados son impredecibles e incontrolables para los actores involucrados. En este sentido, ya a nivel internacional, "participación" se ha convertido en un vocablo de gran utilidad instrumental empleado ya no solamente por académicos en sus estudios de los procesos de democratización sino también por movimientos sociales, organizaciones no gubernamentales, grupos políticos, gobiernos, instituciones financieras internacionales e inclusive, ya entrada la década de 1990, por las empresas privadas de agua y saneamiento multinacionales. De este modo, en muchos casos el concepto ha sido transmutado y aun vaciado de su sentido a través de los usos instrumentales de los que ha sido objeto. Como lo muestra una crecientemente abundante literatura, debido al abuso, el concepto de "participación" social o ciudadana ha ido asumiendo diversos significados e inclusive ha sido convertido en un instrumento de cooptación, manipulación y desmovilización de los actores sociales que luchan por la democratización de la gestión pública. En algunas versiones, la participación es entendida en la práctica como obediencia anticipada por parte de la población con respecto a las decisiones tomadas por expertos y políticos profesionales. En otros casos, en el nombre de la participación se implementan políticas que buscan liberar al estado de sus responsabilidades por la prestación de servicios esenciales y transferir dichas responsabilidades a los ciudadanos y ciudadanas, incluyendo la responsabilidad del financiamiento y de la provisión de fuerza de trabajo voluntaria para la construcción de obras de infraestructura básica. No es sorprendente entonces que algunos autores hayan definido a estas formas instrumentales de participación como "la nueva tiranía" (Cooke y Khotari, 2001).

En este sentido, el tema de la participación social es un aspecto central en relación al gobierno y gestión de los servicios públicos esenciales, noto- riamente en relación a los mecanismos de control democrático sobre el funcionamiento de los organismos y empresas encargados de estos servicios. Este tema nos conecta directamente con el debate sobre la gobernabilidad de los servicios públicos, que se considera a continuación.

\section{La gobernabilidad en la gestión de los servicios de agua y saneamiento}

El concepto de "gobernabilidad" es de desarrollo relativamente reciente y de modo similar a los conceptos modernos de ciudadanía, democracia o sociedad civil, surge de las experiencias específicas de las democracias capitalistas occidentales. Al igual que en el caso de los derechos de ciudadanía que abordamos previamente, las confrontaciones entre distintas tradiciones intelectuales y políticas determinan que el concepto de "gobernabilidad" asuma significados diversos e incluso antagónicos. Por ejemplo, una de sus definiciones más convencionales tiende a presentarlo como la articulación de tres regímenes de gestión: en forma sintética, la gestión pública estatal, la gestión privada mercantil, y la gestión voluntaria y solidaria característica de la "sociedad civil" (ver, entre otros, Picciotto, 1997). Esta concepción de la gobernabilidad, que se ha convertido en dominante en el debate oficial de las políticas públicas, tiene un número de fragilidades importantes. En particular, esa definición presupone un significado universalmente compartido de ciertos conceptos como "sociedad civil", que sin embargo tienen diversas interpretaciones para las distintas tradiciones intelectuales y políticas. Por ejemplo, para la tradición liberal individualista y muy particularmente en su versión neoliberal privatista contemporánea, la "sociedad civil" es sinónimo de "mercado", es decir, una constelación de individuos orientados a la satisfacción egoísta de sus propios intereses en un sistema de mutua competición. Es decir, los campos de acción real para esta tradición político-intelectual se reducen al 
estado y al mercado, y su objetivo central es la reducción del rol del estado a su mínima expresión posible al tiempo que promueve la ampliación máxima de la esfera de influencia de los actores mercantiles. Podemos decir que el ideal neoliberal de la gobernabilidad es la acción privada libre de regulación y control, incluyendo el control ciudadano democrático, tema que retomamos luego con algunos ejemplos. Dado que esta tradición intelectual y política ha dominado a nivel internacional el campo de las políticas públicas, incluyendo las políticas públicas de agua y saneamiento, desde la década de 1980, queda claro que el empleo del concepto de gobernabilidad en la relación a la gestión democrática de los servicios básicos debe ser examinado en profundidad y con escepticismo. Por ejemplo, cuando actores e instituciones fuertemente inspirados por la ideología neoliberal privatista hablan de gobernabilidad en los servicios públicos, es importante preguntarse qué entienden estos actores e instituciones por gobernabilidad. No podemos asumir que existe un concepto de gobernabilidad universalmente aceptado, aunque a veces así se presenta en la literatura de políticas públicas oficial.

Uno de los problemas más importantes que se detectan en el uso del concepto de gobernabilidad en relación a la gestión de servicios públicos esenciales como los de agua y saneamiento es la reducción del concepto al plano técnico-administrativo, instrumental, y su virtual despolitización (Castro, 2007). Por ejemplo, según algunos de los actores más influyentes en el campo de la gestión del agua a nivel global, gobernabilidad se refiere al conjunto de instrumentos técnico-administrativos disponibles para la administración del agua y los bienes y servicios relacionados (GWP, 2003; UNESCO, 2006). En otros casos, y en relación a lo que mencionamos anteriormente, la gobernabilidad tiende a identificarse con el concepto de asociaciones tripartitas entre los gobiernos, la iniciativa privada y la "sociedad civil". En este caso, el concepto de "sociedad civil" se suele utilizar como sinónimo de organizaciones no gubernamentales (ONGs). En general, estas formas de conceptualizar la gobernabilidad reduciéndola a sus dimensiones técnico-administrativas cumplen una función instrumental que parte de vaciar al concepto de uno de sus componentes centrales: el ejercicio del poder. En efecto, la gobernabilidad tiene que ver principalmente con el ejercicio del poder en la toma de decisiones, por ejemplo en relación a la distribución de los beneficios derivados de las inversiones que hace la sociedad en el desarrollo de los bienes y servicios básicos y al control democrático de su gestión por parte de los ciudadanos y las ciudadanas, pero estos aspectos quedan relegados a un segundo plano cuando no directamente excluidos en las conceptualizaciones instrumentales de la gobernabilidad.

En relación al punto anterior, cabe recalcar que la relación entre democracia y gobernabilidad no es necesaria ni mecánica, ya que con frecuencia el ejercicio del poder que caracteriza a la gobernabilidad toma formas autoritarias e incluso antidemocráticas, como es obviamente el caso en las dictaduras cívico-militares pero también recurrentemente en el contexto de las democracias restringidas o de baja intensidad. Como lo señalaran Hanf y Jansen en su trabajo sobre gobernabilidad ambiental en Europa, la gobernabilidad tiene que ver con el ejercicio del poder en relación a los fines y valores que articulan la visión de la sociedad deseada así como también sobre los medios mediante los cuales los actores en determinada sociedad procuran alcanzar dichos fines y defender dichos valores (Hanf y Jansen, 1998). En la práctica, el ejercicio del poder en este sentido tiene que ver con la confrontación entre fines y valores alternativos, a veces antagónicos e incompatibles, que corresponden a las preferencias e intereses materiales de distintos actores socia- 
les. Por esta razón es fundamental superar las visiones idealizadas e ideológicas de la gobernabilidad que la reducen a un conjunto de técnicas de gobierno, supuestamente apolíticas, y restablecer una comprensión de la gobernabilidad que dé centralidad a los procesos políticos y al ejercicio del poder. Como vemos en más detalle en la sección siguiente, este debate tiene una importancia crucial para la gestión democrática de los servicios de agua y saneamiento.

Otro aspecto importante que cabe destacar es que, en forma analógica al tema de la participación social, la gobernabilidad en un ámbito deter- minado de actividad como puede ser el de los servicios de agua y saneamiento básico está enmarcada en el proceso de gobernabilidad en el marco general del sistema social. Como tal, la misma se encuentra imbricada con los procesos de gobernabilidad de otros ámbitos interrelacionados, como por ejemplo la gobernabilidad ambiental, que incluye la gobernabilidad de los ecosistemas acuáticos, de las cuencas, etc., o la gobernabilidad del sistema básico de salud, que incluye los aspectos de salud ambiental y las relaciones entre el acceso a los servicios de agua y saneamiento y la salud pública (ver Figura 2).

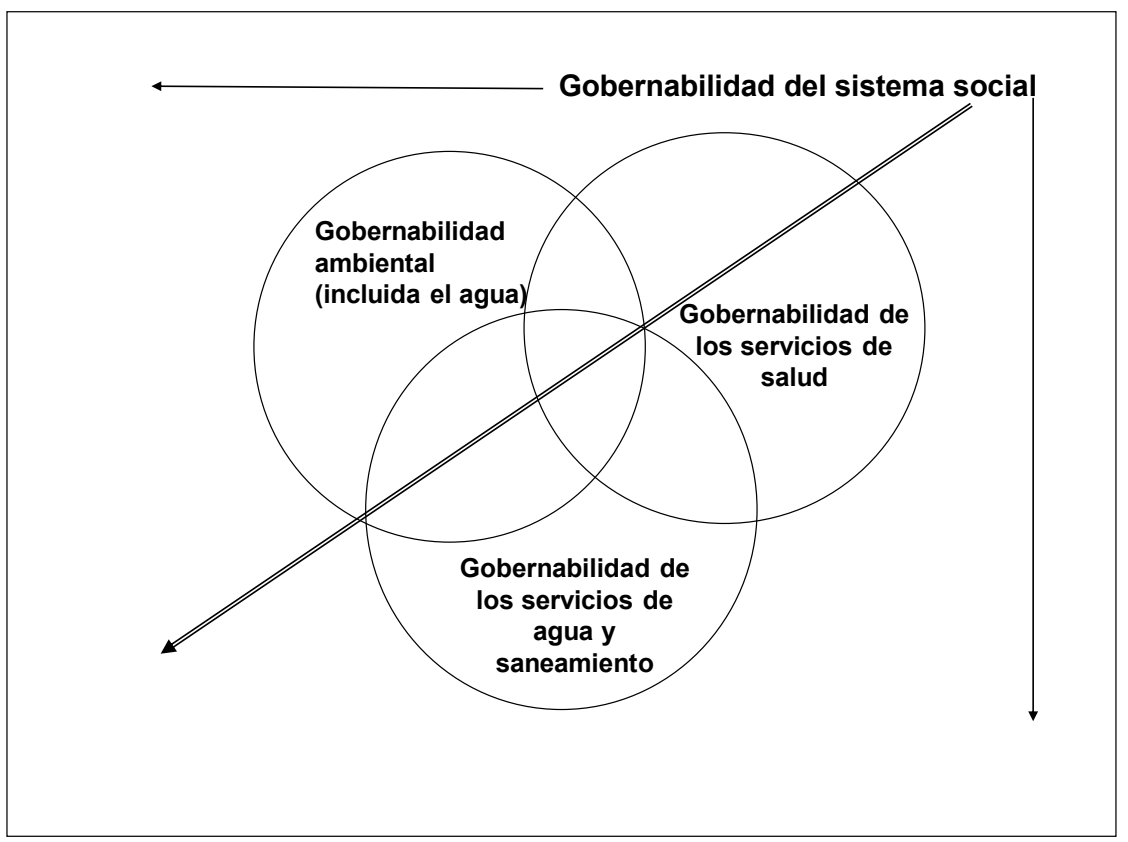

Figura 2. Gobernabilidad inter-sectorial y multi-nivel. Fuente: Elaboración propia.

En este sentido, por ejemplo, sería posible que una determinada sociedad introdujera cambios en el sistema de gobernabilidad de los servicios de agua y saneamiento orientados a la democratización de la gestión -por ejemplo impulsando una legislación que promueva la participación efectiva de los usuarios en el control de la gestión- y que, sin embargo, el impacto potencial de dichas reformas se viera disminuido o incluso neutralizado porque la estructura de gobernabilidad a nivel sistémico sea altamente refractaria al proceso de democratización y tienda a estabilizarse en torno al mantenimiento de las relaciones de poder tradicionales, de carácter tecnocrático, con participación muy restringida, cuando no francamente autoritario. De igual manera, es posible que se introduzcan reformas en la gobernabilidad de estos servicios esenciales orientadas a profundizar el carácter democrático de su gestión pero que simultáneamente otros ámbitos estrechamente vinculados con los servicios de agua y el saneamiento, como son la gestión de las cuencas o 
de la salud pública, tiendan a reproducir formas de gobernabilidad que obstaculicen el proceso democratizador. Claramente, también pueden darse contradicciones y desajustes entre los procesos de gobernabilidad a escalas territoriales diferentes (por ejemplo, entre los niveles nacional, regional y local) o entre ámbitos territoriales de nivel similar (por ejemplo, entre diferentes estados o municipios). Las implicaciones de este carácter inter-sectorial y multi-nivel de la gobernabilidad son efectivamente un aspecto fundamental que debe ser incorporado en el análisis de la gestión democrática de los servicios públicos esenciales.

\section{La gestión democrática de los servicios de agua y saneamiento en perspectiva histórica}

El origen de los servicios de agua y saneamiento en su forma moderna, principalmente en los sectores urbanos de los países occidentales, está estrechamente ligado a los procesos de ciudadanización y de mercantilización. A efectos de síntesis podemos analizar a grandes rasgos este proceso histórico en tres etapas: 1) la etapa "privatista", que abarca desde fines del siglo dieciocho hasta la segunda mitad del siglo diecinueve; 2) la etapa del "racionalismo administrativo", que se establece desde fines del siglo diecinueve y continúa vigente; y 3 ) la etapa "neo-privatista", que desde la década de 1980 intenta reinstalar los principios de la gestión privatista. Necesariamente esta división en etapas con fines analíticos no pretende ser exhaustiva ni que las etapas sean mutuamente excluyentes entre sí, como explicamos a continuación. Sin embargo, estas etapas surgen del análisis de las tendencias centrales observables en el desarrollo de estos servicios en los países capitalistas occidentales, lo que desde luego no implica que no existan variaciones o incluso casos que se alejan de dichas tendencias.

\section{La gestión privatista}

El surgimiento de los primeros sistemas de abastecimiento domiciliar de agua entubada en áreas urbanas a partir de fines del siglo dieciocho en Inglaterra y Francia, los países pioneros en este desarrollo, se da en el marco de las condiciones particulares que caracterizan el desarrollo de la democracia capitalista en estos países (ver, por ejemplo, Mukhopadhyay, 1975; Goubert, 1986; Jenson, 2008). En este marco, la provisión del servicio de agua a los domicilios particulares se da en un comienzo bajo la forma de emprendimientos privados orientados a la ganancia, frecuentemente financiados con recursos públicos. En esta etapa temprana se entendía que el acceso domiciliario al agua en red era una decisión individual, una elección, y dicha provisión tenía un carácter de relación mercantil, privada, entre un proveedor y un cliente. El caso típico de esta forma de prestación del servicio fue la ciudad de Londres, donde hacia mediados del siglo diecinueve la provisión de agua a las viviendas estaba en manos de pequeñas empresas privadas que detentaban monopolios territoriales, un sistema que también se extendió en el resto del país. Procesos similares tuvieron lugar en Francia, Canadá y Estados Unidos, y posteriormente también a nivel internacional (ver por ejemplo, Ogle, 1999; Melosi, 2000; y una selección de casos de las Américas, Europa, África y Asia en Castro y Heller, 2009).

El modelo privatista de gestión se enfrentó desde el comienzo a numerosos obstáculos. Por una parte, el abastecimiento domiciliario de agua orientada a la ganancia privada requería la expansión ampliada de una identidad social que hasta entonces sólo tenía una existencia limitada: el cliente privado y solvente del agua doméstica. La disciplina social requerida para la instalación y reproducción ampliada del cliente privado del agua como identidad social ha sido captada por 
historiadores como Colin Ward, quien registró en su trabajo tanto el carácter excluyente del proceso como las limitaciones del modelo. En efecto, la expansión de servicios de agua privados y orientados a la ganancia dio lugar a la criminalización de quienes por un motivo u otro se resistían a la gestión privatista del agua domiciliaria, o simplemente quedaban excluidos del misma, convirtiendo en "ladrones del agua" a quienes osaran utilizar agua para satisfacer sus necesidades básicas sin firmar primero un contrato con las empresas (Ward, 1997, p. 5). Este proceso de "disciplinamiento" es enteramente comprensible desde la perspectiva del modelo privatista, ya que el mismo se fundaba en el principio de exclusión: el acceso al agua domiciliaria era fundamentalmente un bien privado, disponible solamente a quienes pudieran pagar por él. Es interesante, como ejemplo de este principio fundante de la gestión privatista, que un artículo de The Economist, el vocero histórico y por excelencia del capitalismo liberal británico, escrito tan sólo dos años después de las epidemias de cólera que afectaron a Londres en 1847-48 y en medio de un fuerte debate político con sectores que abogaban por la estatización de las empresas de agua privadas, defendía el modelo privatista diciendo que la ciudad contaba ya con la tecnología para dotar de agua a cualquier vivienda incluso aquellas ubicadas en los puntos más altos de la urbe, siempre y cuando los propietarios estuvieran dispuestos a pagar el precio respectivo. Como para despejar toda duda al respecto del carácter políticoideológico que asu-mía la gestión del agua urbana, el editor agregaba:

"la gran distinción entre Inglaterra y las naciones del continente, la principal fuente de nuestra superioridad, ha sido el gran espacio otorgado a la empresa privada y la muy limitada esfera de operaciones del gobierno. Eventos recientes han reforzado nuestro credo y no podemos permitir que la influencia del terror momentáneo, ocasionado por una epidemia, suprima todas las convicciones morales que han sido tangiblemente la experiencia de los siglos" (The Economist, 1850, p. 62).

De modo similar, el historiador Jean-Pierre Goubert registra el caso de un Comité Consultivo del gobierno francés que en 1819 examinaba una petición de instalación de sistemas purificadores de agua para consumo humano en las poblaciones en la cual los oficiales dictaminan que, aunque la provisión de agua limpia es ciertamente algo deseable, este no es un asunto de gobierno y debe ser resuelto en forma privada (Goubert, 1986, p. 40). Estos ejemplos ilustran la visión dominante en este período. Desde el punto de vista de la gestión democrática, este modelo encarnaba la visión liberal privatista clásica de la ciudadanía, en la cual los derechos se circunscriben a las dimensiones civil y política y, muy particularmente, al derecho a la propiedad privada: el agua domiciliaria constituía una mercancía, un objeto de propiedad privada cuyo intercambio debía ocurrir de acuerdo a las reglas del mercado y sin interferencia del estado. En esta visión, la identidad del ciudadano/a tiende a confundirse casi totalmente con la del/a propietario/a privado/a.

Una de las implicaciones de este carácter excluyente de la gestión privatista de los servicios de agua domésticos, fue la limitación de la expansión de los servicios a las áreas que las empresas consideraban rentables. Este enfoque de servicios de agua orientados a los sectores urbanos que podían ofrecer una demanda solvente condujo al desarrollo de un patrón de alta desigualdad en el acceso al servicio que caracterizó la situación en Europa, Estados Unidos, y posteriormente también en otros países. A esto cabe agregar que el desarrollo de los sistemas del alcantarillado y saneamiento fue prácticamente una tarea exclusiva del sector público, ya que las empresas privadas a cargo de la distribución del agua no se interesaban por el problema del "agua sucia”, entre 
otras razones por la escala de las inversiones necesarias que excedían la capacidad financiera de las empresas y por la escasa potencialidad que presentaban estos servicios para su efectiva comercialización. Por otra parte, durante la etapa privatista y prácticamente hasta la segunda mitad del siglo diecinueve las empresas privadas a cargo de los servicios estaban sujetas a pocos controles, cuando no directamente libres de toda regulación, en términos de calidad y regularidad del servicio, precios, etc. La necesidad de regular a estas empresas comienza a surgir a partir de mediados del siglo diecinueve cuando los problemas y limitaciones de la gestión privatista se hacen cada vez más evidentes en un contexto de rápido crecimiento urbano y poblacional en las ciudades de Europa y Estados Unidos, aunque no será hasta fines del siglo diecinueve que los principios y las instituciones regulatorias de los servicios de agua y saneamiento comienzan a establecerse firmemente.

Efectivamente, desde fines del siglo diecinueve se da un proceso de creciente control y regulación de los servicios de agua prestados por empresas privadas, y una creciente participación del estado, especialmente a través de autoridades locales, en la prestación directa de estos servicios incluyendo el alcantarillado. Un caso notorio fue el de la ciudad de Londres, donde después de varias décadas de confrontaciones políticas un gobierno conservador decide colocar las empresas de agua privada en manos públicas con la creación en 1902 de la Junta Metropolitana de Aguas. Procesos similares tuvieron lugar en el resto de Inglaterra, Europa y Estados Unidos, y posteriormente también en otros países (ver, entre otros autores, Mukhopadhyay, 1975; Ogle, 1999; Melosi, 2000; Pezon, 2000). Uno de los motores de este proceso fue el movimiento higienista, aunque los actores que participaron en estas confrontaciones por la ampliación del acceso a los servi- cios esenciales componían una amplia gama de alianzas que incluían a defensores del libre mercado y de la empresa privada. Como tendencia general, hacia comienzos del siglo veinte se había establecido un cierto consenso sobre la necesidad de concentrar la responsabilidad por el control y gestión de los servicios esenciales en el sector público, lo cual se reflejó en el progresivo desplazamiento del modelo de gestión privatista y la consolidación de lo que, utilizando la definición de John Dryzek, podemos denominar, la gestión "racional administrativa" de los servicios de agua y saneamiento (Dryzek, 1997).

\section{La gestión del racionalismo administrativo}

El concepto de racionalismo administrativo, derivado de los trabajos de Max Weber sobre los procesos de racionalización y burocratización, hace referencia al modelo de gestión que se instalaría crecientemente en los países occidentales a partir de fines del siglo diecinueve y particularmente a comienzos del siglo veinte. El racionalismo administrativo se constituye a partir de la articulación de la creciente aplicación del conocimiento científico y de la organización burocrática gubernamental en el campo de la gestión de recursos, bienes y servicios. La regulación creciente de las actividades privadas que comienza a extenderse a partir de fines del siglo diecinueve forma parte constitutiva del proceso que crecientemente condujo al establecimiento de un modo de gestión centrado en el control e intervención directa del estado en prácticamente todas las esferas de actividad. Este proceso se consolidó a partir de la debacle del sistema de libre mercado en el período de entreguerras que finalmente derivó en el colapso financiero mundial de 1929 (ver entre otros autores que analizan este proceso: Polanyi, 1957; Aglietta, 1976; Hobsbawm, 1994). Como resultado, durante la primera mitad del siglo veinte el racionalismo administrativo desplazó prácticamente por completo al privatis- 
mo como modelo dominante de gestión de los servicios públicos esenciales en el mundo occidental, y a partir de la segunda posguerra puede decirse que instaló un consenso dominante, inclusive entre los defensores del libre mercado, sobre el rol fundamental del estado en la provisión directa de dichos bienes y servicios.

Uno de los resultados indiscutibles del avance y consolidación del racionalismo administrativo en el campo de los servicios esenciales, y en particular los de agua y saneamiento, fue la expansión y eventual universalización del acceso a estos servicios. En la mayoría de los países industrializados, por ejemplo, el acceso a los servicios urbanos de agua para consumo humano se logra universalizar aproximadamente en la década de 1960. En países como Inglaterra, que había sido la cuna del modelo de gestión privatista, la adopción y avance del racionalismo administrativo en la gestión de los servicios de agua y saneamiento en muchos aspectos representó un cambio radical con respecto al pasado. En general, a nivel internacional el avance del racionalismo administrativo se reflejó en la creación de poderosas instituciones públicas dedicadas a la gestión de los servicios urbanos esenciales en la mayoría de los países y también en la estatización generalizada de las empresas privadas de agua, ya que las mismas no podían hacer frente a los requerimientos de expansión y mejora de los servicios en el contexto de un rápido crecimiento urbano y poblacional (ver entre otros: Melosi, 2000; Pezon, 2000; Swyngedouw et al., 2002).

El modelo racional-administrativo de gestión de los servicios de agua y saneamiento comenzó a consolidarse desde fines del siglo diecinueve y progresivamente desplazó al modelo liberal privatista durante la primera mitad del siglo veinte. Los principios fundamentales de este modelo de gestión son:

- La noción de que la provisión de los servicios de agua y saneamiento es afectada por "fallas del mercado" (constituyen un monopolio natural y un bien público de cuyo acceso nadie puede ser excluido; en general requieren economías de escala; generan externalidades positivas y negativas que no pueden ser adecuadamente capturadas por los mecanismos del mercado; son bienes de mérito a nivel de la sociedad pero pueden no ser valorados como tales por los consumidores individuales, etc.).

- La regulación de las empresas privadas de agua domiciliar en nombre del interés público.

- El reemplazo de la empresa privada por la empresa pública como actor central en la gestión del agua domiciliar; el desarrollo de los sistemas de saneamiento por parte de empresas públicas.

- La expansión del control centralizado de los servicios de agua y saneamiento a cargo de entidades públicas (nacionales e internacionales) dotadas de personal técnico-administrativo específicamente capacitado (conformación de hidro-burocracias). La formulación de estándares generales de calidad del servicio bajo el control de estas entidades.

- La expansión de las redes de agua y drenaje sanitario para universalizar el acceso a los servicios, con financiamiento público.

- El reemplazo de las identidades sociales generadas por el modelo privatista (el cliente privado del agua y el ladrón del agua) por la identidad del ciudadano formalmente dotado del derecho al acceso a los bienes y servicios básicos considerados parte de los estándares socialmente aceptados de vida civilizada.

\section{Cuadro 2. Aspectos de la gestión racional-administrativa. Fuente: Elaboración propia.}

Desde otro ángulo, y retomando el debate previo, es importante examinar las contradicciones del modelo de gestión del racionalismo administrativo desde el punto de vista del ejercicio de la ciudadanía. Por una parte, la acción decisiva del estado para la resolución de problemas sociales básicos como el acceso a los servicios esenciales constituyó un paso fundamental en la dirección de una ampliación de los beneficios derivados de la inversión social al conjunto de la población. Este proceso de ampliación concreta del acceso a los servicios básicos esenciales se encontraba estrechamente vinculado con la ampliación de las dimensiones de la ciudadanía que pasaban a incorporar, al menos en el marco de las tradiciones intelectuales y políticas dominantes en Europa, la 
noción de derechos sociales, que sancionaba el principio de que el acceso a los bienes y servicios esenciales debe ser universal, independiente de la capacidad de pago de los individuos y las familias. En las palabras de T.H. Marshall en su análisis clásico de los derechos sociales de ciudadanía, el reconocimiento de estos derechos en la Inglaterra de la segunda posguerra era una respuesta a la exigencia del conjunto de la población que buscaba acceder al disfrute del estándar de vida civilizada logrado por su sociedad, es decir, la exigencia de la mayoría para conseguir "la admisión al [derecho a] compartir el patrimonio común de la sociedad, lo cual a su vez significa una exigencia de ser aceptados como miembros plenos de la comunidad, es decir, como ciudadanos" (Marshall, 1963, p. 72).

Este enfoque representaba una reversión del principio privatista de exclusión. En la visión liberal-social de la ciudadanía defendida por Marshall, el acceso a servicios esenciales que ya formaban parte del estándar de vida civilizada alcanzado por la sociedad inglesa, como el acceso al agua limpia o el drenaje sanitario, ya no podían seguir siendo conceptualizados como una elección individual, un asunto que debía resolverse entre actores privados, una mercancía disponible solamente para quienes podían pagar por ella. El acceso a estos servicios debía ser garantizado por el estado a todos los miembros de la sociedad, con independencia de su posición en el mercado. Los derechos sociales, en esta perspectiva, eran no solamente un elemento componente de la ciudadanía sino que además constituían las condiciones necesarias para el ejercicio pleno de los otros derechos ciudadanos, siempre en el marco de la democracia capitalista.

Ahora bien, y en conexión con el ejercicio de los derechos de ciudadanía, una característica medular del racionalismo administrativo ha sido su verticalidad, fundada en el presupuesto de que el rol central en los procesos de gestión corresponde a los políticos profesionales y a los expertos científicos. En efecto, tradicionalmente el racionalismo administrativo dejó poco espacio a la participación efectiva de los ciudadanos y ciudadanas tanto en la toma de decisiones como en el seguimiento y control democrático de la gestión de los servicios. Mientras que en los países capitalistas centrales este problema tuvo probablemente menos repercusión debido a la gran efectividad del racionalismo administrativo en lograr la expansión y universalización del acceso a los servicios de agua y saneamiento, en los países del así denominado Sur Global, con pocas excepciones, el racionalismo administrativo no logró el mismo nivel de éxito en alcanzar las metas de calidad y universalización de los servicios. No sorprende que en muchos de estos países la tendencia general haya sido la de una gran conflictividad social y política en relación a la gestión de estos servicios esenciales (Castro, 2006).

Por otra parte, las implicaciones del modelo racional-administrativo para la gestión democrática de bienes y servicios esenciales en el medio urbano han sido estudiadas y discutidas en profundidad por diversos autores (ver, entre otros, Preteceille, 1974; Decaillot et al., 1977; Lojkine, 1979; Topalov, 1979). Entre otros aspectos de esta discusión que es importante destacar aquí se encuentra el carácter instrumental de la gestión racional administrativa de bienes y servicios básicos en la superación de la crisis a la que se enfrentaba el sistema capitalista a partir de la gran crisis de 1929. En este sentido, aunque en debates contemporáneos algunas corrientes de opinión tienden a oponer "estado" y "mercado" como si se tratara de campos antagónicos, no menos en relación al tema de la gestión de los servicios de agua y saneamiento, durante la mayor parte del siglo veinte la necesidad de una acción decisiva del estado para garantizar la acumulación 
privada de capital y la propia reproducción del sistema fue un principio aceptado en las políticas públicas dominantes. En este mismo sentido la nueva etapa que consideramos a continuación, el intento de reintroducir el modelo de gestión privatista, se ha caracterizado también por el rol activo del estado en la promoción de dicho modelo, aunque en el debate actual se continúe contraponiendo lo estatal y lo mercantil como si fueran dos esferas naturalmente antagónicas.

Finalmente, es importante destacar que el racionalismo administrativo como modelo de gestión se ha combinado en la práctica con formas de organización política muy diversas que van desde la democracia liberal representativa hasta las dictaduras cívico-militares. En relación con este punto, como discutimos en la sección anterior, el proceso de la gobernabilidad no se reduce solamente al campo de la gestión técnicoadministrativa como lo entienden algunos actores. Por lo contrario, la gobernabilidad tiene que ver sobre todo con el ejercicio del poder en la toma de decisiones con respecto a los fines que debe perseguir una sociedad, los valores y los intereses materiales que se desea defender, y los medios por los cuales se intentará alcanzar dichas metas. En este sentido, como tendencia general, en el marco del racionalismo administrativo ha existido poco espacio para el ejercicio de los derechos políticos de la ciudadanía en la toma de decisiones sobre cuestiones como la gestión de los bienes y servicios públicos, lo que es un aspecto fundamental del proceso de gobernabilidad. Como dice John Dryzek en relación al racionalismo administrativo en el campo de la gestión ambiental, el principio operador de este modelo puede resumirse en la frase "deje estas cuestiones para los expertos" (Dryzek, 1997). Es decir, la participación efectiva de los ciudadanos y las ciudadanas se ha visto severamente restringida en el marco del racionalismo administrativo inclu- so en el contexto de gobiernos democráticos, dado que un presupuesto central de este modelo ha sido el otorgarle virtual exclusividad en la gestión a los expertos científicos y a los administradores y políticos profesionales.

Este enfoque dominante del modelo racionaladministrativo de gestión conduce al planteamiento de una serie de interrogantes en relación al ejercicio de los derechos políticos, que constituyen un componente clave del proceso de gobernabilidad democrática. Por ejemplo: ¿Cuáles son los mecanismos para la designación de los funcionarios y expertos a cargo de la gestión de los servicios de agua y saneamiento en el marco del racionalismo administrativo? ¿Quién los designa y con qué criterios? ¿Cómo se definen las metas que la sociedad debe fijarse en relación a la gestión de los servicios esenciales? ¿Qué valores e intereses materiales se reflejan en dichas metas? ¿A quién pertenecen los valores e intereses materiales en función de los cuales se fijan dichas metas? ¿Quién define los medios por los cuales se tratará de alcanzar dichas metas? ¿Cómo se llega a esa definición? ¿Qué mecanismos tienen los ciudadanos y las ciudadanas para ejercer control sobre los actores e instituciones que están a cargo de estas decisiones y de su implementación? Las respuestas a estas y otras preguntas de orden similar en general conducen a la conclusión de que el racionalismo administrativo, incluso cuando ha tenido éxito en sus objetivos concretos como la universalización del acceso a los servicios esenciales, se ha caracterizado por combinarse con formas de gestión democrática restringida, verticales, poco participativas, cuando no con formas de gestión directamente autoritarias o incluso dictatoriales. Este hecho fue utilizado precisamente con gran éxito por los abogados del retorno al modelo privatista de gestión a partir de la década de 1980, que han utilizado el carácter poco participativo del racionalismo administrativo 
como una excusa para promover la desregulación, la liberalización y la privatización de estos servicios. Como vemos en la siguiente sección, este desarrollo reciente tiene consecuencias importantes para la gestión democrática de los servicios de agua y saneamiento.

\section{La gestión neo-privatista}

Esta etapa, que cubre el período más reciente de la evolución de los servicios de agua y saneamiento, particularmente a partir de la década de 1980 , está marcada por la introducción de reformas orientadas a reemplazar el modelo de gestión basado en el racionalismo administrativo por una versión actualizada del privatismo que había imperado hasta fines del siglo diecinueve. Por falta de espacio no me detendré a discutir aquí los detalles de este proceso, que han sido desarrollados por numerosos autores. Lo que es importante destacar aquí son las principales tendencias de esta etapa, incluyendo las posibles trayectorias futuras, resaltando las relaciones e implicaciones de este modelo para la gestión democrática de estos servicios públicos esenciales.

En conexión con lo anterior, cabe destacar que aunque la promoción de las políticas que buscan instalar un modelo de gestión neo-privatista de los servicios de agua y saneamiento frecuentemente se ha intentado justificar como una respuesta a la crisis interna de estos servicios, en la práctica el origen de estas políticas ha tenido muy poco o nada que ver con los problemas propios de estos servicios. En general, la aplicación de políticas neo-privatistas ha formado parte del así llamado Consenso de Washington que otorgó un marco ideológico y político para estas reformas en prácticamente todos los campos de actividad, incluyendo la gestión de los servicios básicos (ver, entre otros, Leys, 2001; Harvey, 2005). A pesar de que desde comienzos del siglo veintiuno el proceso político a nivel internacional, y notoria- mente en América Latina, ha tendido a cancelar o al menos limitar el alcance de ciertos aspectos importantes del Consenso de Washington, estas reformas han instalado mecanismos y han desatado fuerzas cuya dinámica inercial continúa y probablemente continuará influyendo y hasta determinando las formas de gobernabilidad $y$ gestión en casi todos los ámbitos, incluyendo el de los servicios de agua y saneamiento.

En este sentido, las políticas neo-privatistas en relación con estos servicios se han caracterizado fundamentalmente por el intento de transferir el control, y en los casos más radicales incluso la propiedad, de la gestión de los mismos a la iniciativa privada por distintos medios. Por ejemplo, el Banco Mundial, una de las instituciones que ha impulsado con más fuerza las reformas neoprivatistas en décadas recientes, creó un Grupo para la Participación del Sector Privado en Infraestructura al que se le encomendó la tarea de aumentar la "participación privada en infraestructura dentro del contexto de los objetivos generales [del Banco] de apoyar la reducción de la pobreza y el desarrollo sustentable" (Banco Mundial, 1998). El Programa de Acción del Grupo declara que:

"La participación privada ofrece un enorme potencial para mejorar la eficiencia de los servicios de infraestructura, extender su distribución hacia los pobres, y aliviar la presión sobre los presupuestos públicos que, por mucho tiempo, fueron la única fuente de financiamiento. Incentivar una mayor implicación privada requiere que los gobiernos cambien su papel, en el sentido de no proporcionar servicios de infraestructura en forma directa sino más bien fomentar la competencia entre proveedores privados, regulando en aquellos lugares donde la competencia es débil, y apoyando al sector privado en general" (Banco Mundial, 1998, p. 1).

Es decir, la estrategia central de estas reformas ha sido la de desplazar al estado de la función de prestación directa de los servicios, que deberían 
ser transferidos a empresas privadas, y limitar la función de control y regulación estatal de las empresas privadas al mínimo posible, efectivamente transformando el rol del estado en el de soporte y garante de la gestión privada de los servicios esenciales. En otras palabras, en la visión neoprivatista se trata de restablecer la noción del estado mínimo característica del liberalismo individualista, que en su versión contemporánea dictamina que el estado ya no debe jugar el rol de garante y responsable del acceso universal de la población a los servicios básicos, como lo fue durante la mayor parte del siglo veinte. En las nuevas condiciones promovidas por el neoprivatismo, los servicios básicos deben volver a tener el estatus de mercancía, de bienes privados que deben ser adquiridos en el mercado sin mediación del estado. Por ejemplo, en un documento del Banco Mundial que promueve el modelo neoprivatista de gestión como solución para extender el acceso a los servicios de agua y saneamiento a los pobres los autores sugieren que uno de los obstáculos más importantes a la introducción de las reformas es que:

"el público se ha acostumbrado [a la prestación de los servicios de agua y saneamiento por empresas públicas] y percibe a estos servicios como un «servicio público» o inclusive como un «bien social»" (WSP-PPIAF, 2002, p. 8).

En otras palabras, según el documento es necesario desterrar la noción de que el acceso a los servicios esenciales de agua y saneamiento es una responsabilidad del estado y un derecho de todas las personas, y más bien debe instalarse la noción de que las personas son responsables de comprar estos servicios en forma privada ${ }^{5}$. Este

\footnotetext{
${ }^{5}$ Cabe explicitar que este aspecto no debe confundirse con el problema del pago por los servicios. Obviamente, que los servicios sean considerados un bien público o social no implica que los mismos sean gratuitos, aunque el principio de universalización asociado con la noción de bien público o social sí implica la provisión de mecanismos que garanticen el acceso a los servicios incluso a quienes no pueden pagar por ellos. Tradicionalmente la solución en el marco de la gestión racional administrativa ha sido una combinación de políticas
}

principio central de la iniciativa neo-privatista también está siendo promovido por algunos sectores dentro de las instituciones especializadas de las Naciones Unidas, como lo muestra el Segundo Informe Mundial del Agua de la UNESCO, en el cual se clasifica a los servicios de agua y drenaje sanitario domiciliar como "bienes mercantiles o privados" (UNESCO, 2006, p. 409). Es importante recalcar aquí nuevamente que este tema no debe confundirse con el clásico debate "público vs. privado" en la gestión de los servicios de agua y saneamiento que se ha tenido lugar en años recientes. El punto principal aquí es que la reforma neo-privatista busca reformular completamente el rol del estado y el estatus de los servicios básicos, con independencia del tipo de operador del servicio, es decir, incluso si el prestador es una empresa pública.

En la práctica, las formas predominantes asumidas por esta política en relación a los servicios públicos esenciales han sido las concesiones y los contratos parciales a empresas privadas $\mathrm{y}$, más recientemente, las así llamadas asociaciones público-privadas (Hall, 2008). Si bien estas políticas se han ido implementando a nivel global desde la década de 1980 (aunque algunos experimentos ya se habían realizado previamente en Chile durante la década previa), esta implementación ha avanzado a velocidades y en secuencias diferentes en los distintos territorios. Por ejemplo, en Inglaterra y Gales el gobierno de Margaret Thatcher procedió a la privatización completa (full divestiture) de las empresas de agua y saneamiento en 1989, un sistema que con algunas modificaciones sigue vigente hasta la fecha de escribirse este artículo. En cambio en los Estados

que incluye desde subsidios estatales directos financiados con impuestos o deuda pública, subsidios cruzados entre usuarios, y otros mecanismos redistributivos. La política neo-privatista tiende a eliminar estos mecanismos en principio, aunque en la práctica ya existen casos en que el fracaso del modelo privatizador ha obligado a la reinstalación de mecanismos redistributivos (aunque con frecuencia la principal razón ha sido la de garantizar el ingreso de las empresas privadas cuando la base de usuarios tiene una alta incidencia de falta de pago). 
Unidos, por ejemplo, la mayor parte de la población de ese país (alrededor del 85\%) sigue siendo atendida por empresas públicas ya que en general no se ha optado por la posibilidad de transferir estos servicios al sector privado, a pesar de que el gobierno de ese país ha sido uno de los principales promotores de las políticas neo-privatistas en el resto del mundo. En América del Sur, Chile y Argentina han sido los dos países que más avanzaron en la implementación de las políticas neo-privatistas. En el caso de Argentina, el gobierno del Presidente Carlos Menem (1989-1999) realizó una transferencia masiva de las empresas públicas al sector privado, lo cual en el caso de los servicios de agua y saneamiento implicó que entre 1993 y 1999 se pasara del $0 \%$ al $70 \%$ de la población atendida por operadores privados. En cambio en Brasil, a pesar de los esfuerzos del Presidente Fernando Henrique Cardoso (19952002) por profundizar las reformas neo-privatistas durante la década de 1990 , la proporción de la población atendida por empresas privadas de agua y saneamiento no pasó del $10 \%$ durante esa década, una figura que es aún menor en otros países como México. Sin embargo, mientras que las experiencias negativas con las reformas neoprivatistas han llevado a un número importante de gobiernos a la decisión de cancelar las reformas y recuperar las empresas públicas, incluyendo casos en Argentina, Bolivia, China, Estados Unidos, Francia, Tanzania, y Uruguay, entre muchos otros, en otros casos, incluyendo Brasil y México, la aceleración y profundización del proceso ha comenzado más tarde (Balanyá et al., 2005; Castro, 2008).

Las consecuencias de las reformas neoprivatistas en relación a los servicios públicos esenciales desde la perspectiva de la gestión democrática de estos servicios son múltiples y en su mayor parte regresivas. No me detengo aquí a examinar las consecuencias de los procesos con- cretos de expansión de la participación privada, incluyendo la privatización total o parcial de los servicios, que ya han sido objetos de numerosos trabajos (ver entre otros: Bakker, 2004; McDonald y Ruiters, 2004; Swyngedouw, 2005; Mulreany et al., 2006; Castro, 2010). Más bien me concentraré aquí en los aspectos conceptuales y en las previsibles tendencias de este proceso. Un punto central que debe recalcarse, como anticipamos previamente, es que los mecanismos y las fuerzas puestos en marcha por las reformas neoprivatistas trascienden la dicotomías retóricas de "estado vs. mercado" o "público vs. privado", ya que estas reformas han logrado instalar los principios y valores del privatismo en el funcionamiento del propio estado y de las instituciones públicas, incluyendo las empresas públicas de agua y saneamiento. Un ejemplo reciente procedente de Uganda permite ilustrar este punto:

"No hace todavía un año desde que el agua limpia comenzó a llegar al centro de salud Tiriri en Katine, en el nordeste de Uganda, y el servicio ha sido cortado hace ya dos meses porque el centro no tiene dinero para pagar la cuenta del agua. La Corporación Nacional de Agua y Saneamiento (NWSC) desconectó el suministro hace dos meses dado que las autoridades de salud no pagaron la cuenta de más de 600,000 chelines ugandeses [unos 170 euros]. Las autoridades dicen que no hay dinero para pagar la deuda. La decisión ha despertado la preocupación entre los pacientes y los trabajadores del hospital de que la falta de agua limpia podría producir la proliferación de infección. La parte más afectada es la sala de maternidad. [...] El año pasado el gobierno de Uganda construyó una extensión de $7 \mathrm{~km}$ de la red de agua que sirve al distrito vecino de Kaberamaido hasta Katine, particularmente beneficiando al centro de salud. [...] Pero el gobierno no planificó en detalle la forma en que los servicios de salud deberían pagar sus cuentas de servicios y muchas autoridades en Uganda están teniendo dificultades para pagar el agua y la electricidad. Aun más, como la atención médica es gratuita en 
las instalaciones del gobierno, el centro de salud no tiene fuentes alternativas de financiamiento. La desconexión ahora significa que el centro de salud debe depender del agua de lluvia, pozos de calidad cuestionable y agua insalubre procedente de pantanos" (Malinga, 2009).

Uganda es uno de los principales ejemplos en África de la implementación de las reformas neoprivatistas en el gobierno y gestión de los servicios públicos esenciales, en particular la reforma del sector público mediante la introducción de las políticas de recuperación total de costos (eliminación completa de subsidios) como antesala para la posterior privatización de los servicios básicos, un caso que el Banco Mundial y otros actores que promueven las reformas neo-privatistas presentan como un ejemplo del éxito de dichas políticas (ver, por ejemplo, Jones et al., 2008). Este no es un ejemplo aislado, pero es un caso reciente que ilustra la continuidad de una política cuyos resultados regresivos ya han sido convincentemente demostrados en muchos países. El principal punto que deseo ilustrar con este ejemplo es la cancelación de la noción de derecho universal a un servicio esencial para la vida digna, como el agua limpia, y su reemplazo por el principio de exclusión: el agua es solamente para quien puede pagar por ella, una regla que se aplica inclusive a las propias instituciones públicas responsables de servicios esenciales para la vida como el cuidado de la salud (ver por ejemplo Mulreany et al., 2006).

En este sentido, por una parte, y en relación a los derechos de ciudadanía, las políticas neoprivatistas constituyen un ataque a la visión social liberal de la ciudadanía que había predominado desde mediados del siglo veinte. Si se acepta nuestro argumento inicial de que incluso los derechos sociales de ciudadanía son apenas un reconocimiento formal de las desigualdades estructurales de la democracia capitalista, que son sólo un paliativo frágil para combatir el impacto real de dichas desigualdades, y que en la práctica en muchos países la institucionalización de dichos derechos ha sido fragmentaria e inconsistente, entonces su abolición y sustitución por los principios del privatismo decimonónico constituyen un retroceso injustificable. Tomando prestadas las palabras de Eric Hobsbawm, la cancelación de los derechos sociales y el retorno al principio privatista de exclusión constituye otro paso en el proceso de "barbarización" que se expresa en la reversión "de las reglas y estándares de conducta moral que habían sido encarnadas en las instituciones de los estados dedicadas al progreso racional de la humanidad" (Hobsbawm, 1997, p. 253-254).

Ahora bien, incluso si limitamos los derechos de ciudadanía a las dimensiones civil y política, como es el caso en la versión liberal individualista de la democracia capitalista, todavía es posible realizar una crítica de las políticas neo-privatistas en el campo de los servicios de agua y saneamiento, ya que la aplicación lógica de los principios de la ciudadanía civil y política pueden tener consecuencias de alcance potencialmente radical. Por ejemplo, consideremos brevemente algunas de las consecuencias de las reformas neoprivatistas para la gestión democrática de los servicios de agua y saneamiento:

- El diseño e implementación de estas reformas, con pocas excepciones, se ha realizado en contra de la voluntad de las mayorías ciudadanas. En la mayoría de los casos reformas como la privatización de los servicios de agua y saneamiento se han implementado por decreto o sin debate público, incluso sin debate legislativo. Este fue el caso por ejemplo en Inglaterra, en donde Margaret Thatcher privatizó los servicios de agua y saneamiento en 1989 , aunque la opinión pública mayoritariamente se oponía a esta política. Este ha sido también el caso en prácticamente todos los países de 


\section{América Latina.}

- En los pocos casos en los que se ha llamado a consulta pública a través de plebiscitos u otras formas de participación abierta de la población, como ocurrió por ejemplo en la provincia de Chaco, Argentina, en 1994, en el Uruguay en 2004, o en Italia en junio de 2011 (mientras se escribe este artículo), la población masivamente rechazó la implementación de las reformas privatistas (Roze, 2003; Santos y Villarreal, 2005).

- En general, la implementación de estas reformas, particularmente las diversas versiones de la privatización, se han realizado sin la provisión de mecanismos de regulación y control ciudadano mínimos. El establecimiento de mecanismos de control y regulación ha sido históricamente el resultado de las demandas de la población a causa de los problemas con la calidad de los servicios o por abusos de los operadores. Pero aun en estos casos la ciudadanía tiene muy poca capacidad de control de la gestión de estos servicios básicos, incluso en países con una larga tradición de instituciones de regulación y control como Inglaterra (ver, por ejemplo, el crítico informe de Yarrow y otros sobre los fallos de la regulación de los servicios de agua y saneamiento en Inglaterra: Yarrow et al., 2008; para el caso de América Latina, véase, por ejemplo, Solanes, 2002).

\section{Conclusiones: los desafíos que enfrenta el proceso de democratización de la gestión de los servicios públicos esenciales}

Como se dijo al comienzo de este artículo, al hablar de gestión democrática de los servicios de agua y saneamiento nos referimos al proceso de democratización substantiva, no meramente a las versiones de la democracia formal, retórica. Este planteamiento me llevó a considerar en cierto detalle algunos elementos fundamentales del pro- ceso de democratización así entendido, en particular la relación entre el desarrollo de los servicios de agua y saneamiento y el proceso de ciudadanización, así como los modelos sucesivos de gobernabilidad de estos servicios esenciales. Para concluir, deseo hacer hincapié en algunos de los desafíos más importantes que se pueden identificar en relación con la posibilidad de profundizar en el proceso de democratización en la gestión de estos servicios básicos.

Un aspecto importante del proceso de democratización substantiva de la gestión de los servicios de agua y saneamiento tiene que ver con la producción de conocimiento. Históricamente la producción de conocimiento sobre el agua, el ambiente y los servicios públicos esenciales ha sido fundamentalmente una tarea reservada a las disciplinas tecno-científicas. Sin embargo, crecientemente se reconoce, al menos retóricamente, que los complejos problemas que presenta la gestión de los bienes y recursos naturales, incluyendo la gestión de servicios como los de agua y saneamiento, en un contexto de profundas transformaciones socio-ecológicas, son de carácter multidimensional y requieren la adopción de enfoques inter y trans-disciplinarios. Sin embargo, existen obstáculos significativos para el desarrollo de enfoques que transciendan los límites monodisciplinarios y además incorporen a los actores no académicos (como por ejemplo las comunidades de usuarios) en la producción y validación del conocimiento.

Por una parte, a pesar del reconocimiento retórico de la necesidad de mayor inter-disciplinaridad, la institucionalización de la producción de conocimiento sigue en gran medida el modelo centrado en torno a disciplinas especializadas en aspectos específicos. A pesar de los esfuerzos importantes realizados en este campo, el avance en la búsqueda de niveles de coordinación interdisciplinaria cada más elevados, ha sido lento y fragmenta- 
rio. En el caso de los servicios de infraestructura básica como el agua y el saneamiento ha habido importantes avances, especialmente con la creciente participación de las ciencias sociales, en sentido amplio, incluyendo la economía, las ciencias de la administración, el derecho y los estudios históricos, pese a lo cual persisten fracturas importantes, especialmente entre las disciplinas tecno-científicas y el resto. En muchos sentidos, sigue predominando la noción de que la gestión de servicios públicos esenciales es una cuestión fundamentalmente técnica. En consecuencia, incluso las contribuciones a este tema provenientes de las ciencias sociales con frecuencia también tienden a centrarse en los aspectos más técnicos, como la formulación e implementación de políticas públicas, las reformas legales e institucionales, o el diseño y aplicación de sistemas de administración y gestión de empresas. El problema de la democratización de la gestión de los servicios, que es un problema fundamentalmente político, suele quedar marginalizado como objeto de conocimiento legítimo en este campo. Este es sólo un ejemplo, aunque muy importante, de la necesidad de promover mayores oportunidades de articulación entre las diversas disciplinas comprometidas con la producción de conocimiento sobre el gobierno y la gestión de los servicios públicos esenciales.

Por otra parte, existe un creciente reconocimiento del hecho de que la producción y validación del conocimiento no se restringe al ámbito académico y profesional, sino que existe una gama más amplia de actores sociales que participan en el proceso. Las nociones de trans-disciplinaridad y de ciencia posnormal intentan capturar este aspecto del proceso de producción de conocimiento (Funtowicz y Ravetz, 1994), el cual reviste gran relevancia para la democratización de la gestión de los servicios de agua y saneamiento. Este punto está estrechamente conectado con el proceso de ciudadanización en relación, en este caso, a la gestión de los servicios básicos. En efecto, la expansión y universalización de estos servicios en los países occidentales, especialmente en las áreas urbanas, fue posible en el contexto de la adopción de los principios del racionalismo administrativo, que otorgó la primacía a los expertos tecno-científicos y a los políticos profesionales en la gestión de los servicios públicos esenciales. Sin duda el éxito logrado en relación a estos servicios en las democracias capitalistas centrales hacia mediados del siglo veinte se debió en gran medida a la decisión política de fundar la gestión de estos servicios sobre la base del conocimiento científico y la pericia administrativa de un sector público profesionalizado con el objetivo de satisfacer las necesidades colectivas de la población. Sin embargo, uno de los aspectos más frágiles del racionalismo administrativo como modelo de gestión de los servicios de agua y saneamiento ha sido el escaso espacio otorgado a la participación democrática, al ejercicio de los derechos ciudadanos de acceso al conocimiento sobre cómo se gobiernan y gestionan estos servicios de interés público, y sobre todo al control democrático de la gestión.

Lamentablemente, las reformas neo-privatistas implementadas desde la década de 1980, como tendencia general, han tendido a reproducir e incluso empeorar estas condiciones, haciendo aún más difícil el acceso a la información y el control democrático de la gestión. Por ejemplo, uno puede preguntarse a modo de ilustración, cuando el Segundo Informe Mundial del Agua de la UNESCO citado declara que los servicios de agua y drenaje sanitario domiciliar son "mercancías, bienes privados" (UNESCO, 2006, p. 409), o cuando el Banco Mundial en sus documentos de promoción de reformas neo-privatistas arguye que la población incorrectamente cree que estos servicios son "un bien público o inclusive un bien 
social", ya que los mismos son efectivamente una mercancía en la visión de estas instituciones (WSP-PPIAF, 2022, p. 8): ¿Cómo han llegado a estas conclusiones? ¿Quién se puede autoasignar el derecho de decidir en nombre de la ciudadanía que estos servicios son una mercancía, un bien privado, y ya no un servicio público o un derecho social? ¿Con quién discutieron estas cuestiones? ¿Cuál fue el proceso de elaboración conceptual que los lleva a defender esas afirmaciones? ¿Los intereses de quiénes están defendiendo? Evidentemente, más allá de la retórica democrática de estas instituciones, en la práctica sus argumentos reproducen un modelo de construcción de conocimiento y de desarrollo e implementación de políticas públicas que se funda en la exclusión de la participación de la ciudadanía. Además, dichos argumentos claramente reflejan preferencias ideológico-políticas e ignoran el conocimiento acumulado históricamente en relación a los principios y modelos que garantizaron la efectiva universalización de los servicios públicos esenciales en los países que lograron su objetivo. El análisis previo puede aplicarse por analogía a otros aspectos de la gestión de estos servicios. En este sentido, como aclaramos previamente, el impacto de las reformas neo-privatistas no se limita a los muy publicitados debates entre lo "público" y lo "privado" o el "estado" y el "mercado", que han ocupado a buena parte de la literatura reciente sobre el tema. Más bien, las reformas neo-privatistas también están transformando el marco y las formas de operación de los organismos públicos, incluyendo las empresas públicas de agua y saneamiento, a las cuales se les exige crecientemente que operen como empresas privadas. De este modo, con independencia del carácter privado o público de estas empresas, las mismas se ven obligadas a dar prioridad no a la satisfacción de las necesidades del conjunto de la población sino a la eficiencia económica de su funcionamiento, incluyendo la generación de utilidades. Estas empresas, incluso siendo de propiedad pública, crecientemente deben dar cuenta prioritariamente a sus inversores y accionistas (algunas empresas públicas, por ejemplo en Brasil, cotizan una proporción substancial de sus acciones en la bolsa de valores) antes que a los ciudadanos y ciudadanas de los territorios en los que prestan el servicio, quienes prácticamente no tienen instrumentos a su disposición para ejercer control democrático sobre la gestión. Este es uno de los desafíos cruciales que confronta la democratización de la gestión de los servicios esenciales en el marco de las reformas neo-privatistas en marcha.

Finalmente, y en relación con este último punto, es muy importante reafirmar el hecho de que el proceso de democratización tiene lugar a la escala del sistema social, no es posible pensar en el "sector" de los servicios de agua y saneamiento como un compartimiento estanco sino que más bien el mismo se encuentra integrado en una gran complejidad sistémica de orden creciente, en particular en relación con las rápidas transformaciones socio-ecológicas que están teniendo lugar aceleradamente (baste mencionar brevemente aquí las presiones del cambio climático sobre la disponibilidad de agua para consumo humano en las grandes ciudades en un contexto de expansión sostenida de la población urbana a nivel mundial). En el presente contexto histórico, la defensa de las conquistas logradas en el campo de los servicios públicos esenciales en el curso del siglo veinte parece constituirse en una empresa radical, casi revolucionaria, a pesar de que, en la práctica y observados en una perspectiva histórica de largo plazo, dichas conquistas constituyeron tímidos avances en el proceso de democratización de la sociedad. En este sentido, la defensa y expansión de los derechos sociales de la ciudadanía burguesa, capitalista, que formalmente 
intentan establecer el reconocimiento del derecho de las mayorías a compartir los beneficios de los estándares de vida social alcanzados por una determinada comunidad política, se han convertido en uno de los frentes de la confrontación al avance generalizado del neo-privatismo. Sin embargo, incluso si venciesen las fuerzas sociales comprometidas en la defensa de esas tímidas conquistas, como es el derecho a unos pocos litros diarios de agua limpia por persona y a sistemas de drenaje sanitario que permitan el disfrute de condiciones de vida mínimamente dignas con independencia de la capacidad económica de las personas, se trataría apenas de un paso más en la larga marcha por la democratización substantiva de la sociedad.

\section{Referencias}

AGLIETTA, Michel. A theory of capitalist regulation. The US experience. London: CalmannLévy, 1976.

ANDERSON, Benedict. Imagined communities. London/ New York: Verso, 1983.

BAKKER, Karen J. An uncooperative commodity privatizing water in England and Wales. Oxford: Oxford University Press, 2004.

BALANYÁ, Belén; BRENNAN, Brid; HOEDEMAN, Olivier; KISHIMOTO, Satoko \&TERHORST, Philipp. Reclaiming public water. Achievements, struggles and visions from around the world. London: Transnational Institute and Corporate Europe Observatory, 2005, p. 173-179.

BANCO MUNDIAL. Facilitating private involvement in infrastructure: an action programme. Washington D.C.: Banco Mundial, Grupo de Trabajo sobre Infraestructura, 1998.

BEBBINGTON, Anthony J.; BEBBINGTON, Denise; BURY, Jeffrey; LINGAN, Jeannet; MUÑOZ, Juan Pablo \& SCURRAH, Martin. Mining and social movements: struggles over livelihood and rural territorial development in the Andes. World
Development, 2008, vol. 36, n 12, p. 28882905.

BOELENS, Rutgerd Anne. The rules of the game and the game of the rules. Normalization and resistance in Andean water control. Wageningen: Wageningen University Press, 2008.

BRUBAKER, Rogers. Citizenship and nationhood in France and Germany. Cambridge, Mass. I London: Harvard University Press, 1992.

CARVALHO, Jose Murilo de. Desenvolvimiento de la ciudadanía en Brasil. México DF: El Colegio de México y Fondo de Cultura Económica, 1995.

CASTRO, J. Esteban. Private sector participation in water and sanitation services in the context of globalization: is it the right answer to public sector failures? In RINGER, C.; BISWAS, A.K. \& CLINE, S.A. (Eds.). Globalization, trade, and global change: implications for water and food security. New York: Springer, 2010.

CASTRO, J. Esteban. Neoliberal water and sanitation policies as a failed development strategy: lessons from developing countries. Progress in Development Studies, 2008, vol. 8, n 1, p. 6383.

CASTRO, J. Esteban. Water, power, and citizenship. Social struggle in the Basin of Mexico. Houndmills / Basingstoke / New York: PalgraveMacmillan, 2006.

CASTRO, J. Esteban. \& HELLER, Léo. (Eds.). Water and sanitation services: public policy and management. London / Sterling, VA: Earthscan, 2009.

COOKE, Bill \& KOTHARI, Uma. Participation: the new tyranny? London: Zed Books, 2001.

CRESPO, Carlos O. Privatización del agua y racismo ambiental en ciudades segregadas. Anuario de Estudios Americanos, 2009, vol. 66, $n^{\circ} 2$ (número interdisciplinario especial sobre Agua, Ambiente y Territorios en América Latina, coordinado como editores por CASTRO, J.E. y 
SIMÓN RUIZ, I.), p. 105-122.

DAGNINO, Evelina. (Ed.). Os anos 90: política e sociedade no Brasil. São Paulo: Brasiliense, 1994.

DÁVALOS, Pablo. (Ed.). Pueblos indígenas, estado y democracia. Buenos Aires: Consejo Latinoamericano de Ciencias Sociales (CLACSO), 2005.

DECAILLOT, Maurice; PRETECEILLE, Edmond et TERRAIL, Jean-Pierre (Eds.). Besoins et mode de production. Paris: Editions Sociales, 1977.

DELANTY, Gerard. Citizenship in a global age: society, culture, politics. Philadelphia, PA.: Open University Press, 2000.

DRYZEK, John S. The politics of the earth. Environmental discourses. Oxford: Oxford University Press, 1997.

DUTRA, Olivio e BENEVIDES, Maria Victoria. Orçamento participativo e socialismo. São Paulo: Perseu Abramo, 2001.

ESCALANTE GONZALBO, Fernando. Ciudadanos Imaginarios. México D.F.: El Colegio de México, 1992.

ESCH, Sophie; DELGADO, Martha; HELFRICH, Silke; SALAZAR RAMÍREZ, Hilda; TORREGROSA, María Luisa y ZÚÑIGA PÉREZTEJADA, Iván (Eds.). La gota de la vida: hacia una gestión sustentable y democrática del agua. México DF: Fundación Heinrich Böll Editions, 2006.

FALLON Jr.; Richard H. \& MELTZER, Daniel J. Habeas Corpus jurisdiction, substantive rights, and the war on terror. Harvard Law Review, 2007, vol. $120, n^{\circ} 8$, p. 2029-2112.

FEDOZZI, Luciano. Orçamento participativo. Reflexões sobre a experiência de Porto Alegre. Porto Alegre: Tomo Editorial y FASE, 2001.

FERREE, Mira Marx; GAMSON, Willliam A.; GERHARDS, Jürgen \& RUCHT, Dieter. Four models of the public sphere in modern democ- racies. Theory and Society, 2002, vol. 31, $\mathrm{n}^{\circ} 3$, p. 289-324.

FLEURY, Sonia. Estados sin ciudadanos. Seguridad social en América Latina. Buenos Aires: Lugar Editorial, 1997.

FUNTOWICZ, Silvio O. \& RAVETZ, Jerome R. The worth of a songbird: ecological economics as a post-normal science. Ecological Economics, 1994, vol. 10, $\mathrm{n}^{\circ} 3$, p. 197-207.

GARCÉS, Mario; GIRÁLDEZ, Soraya; GOLDAR, María Rosa; ALBUQUERQUE, Maria do Carmo; RIQUELME, Quintín y BURONI, Teresa. Democracia y ciudadanía en el MERCOSUR. Santiago de Chile: LOM Ediciones, 2006.

GIRAUDO, Laura (Ed.). Ciudadanía y derechos indígenas en América Latina: Poblaciones, estados y orden internacional. Madrid: Centro de Estudios Políticos y Constitucionales, 2007.

GLENN, Evelyn. Citizenship and inequality: historical and global perspectives. Social Problems, 2000, vol. $47, n^{\circ} 1$, p. 1-20.

GLOBAL WATER PARTNERSHIP (GWP). Effective water governance. Learning from the dialogues. Estocolmo: GWP, 2003. Originalmente disponible en <http://www.gwpforum.org/gwp/library/Effective_ Water_Governance.pdf>. (Consultado en noviembre de 2009).

GOLDHABER, Michael D. A people's history of the European Court of Human Rights. New Jersey: Rutgers University Press, 2009.

GOODIN, Robert E.; PATEMAN, Carole \& PATERMAN, Roy. Simian Sovereignty. Political Theory, 1997, vol. 25, n 6, p. 821-849.

GOUBERT, Jean-Pierre. The conquest of water. The advent of health in the industrial age. Cambridge: Polity Press / Oxford: Basil Blackwell, 1986.

GRAY, Chris H. Cyborg citizen: politics in the posthuman age. New York / London: Routledge, 2001. 
HALL, David. Public-Private Partnerships (PPPs) in the EU - a critical appraisal. Londres: Universidad de Greenwich, Unidad de Investigación de la Internacional de Servicios Públicos, 2008. Disponible en <www.psiru.org/reports/2008-11PPPs-crit.doc>. (Consultado el 18 de junio de 2011).

HANF, Kenneth \& JANSEN, Alf-Inge (Eds.). Governance and environmental quality: environmental politics, policy and administration in Western Europe. Harlow: Addison Wesley Longman, 1998.

HARVEY, David. A brief history of neoliberalism. Oxford: Oxford University Press, 2005.

HOBSBAWM, E. On History. New York: The New Press, 1997.

HOBSBAWM, Eric. Age of extremes. The short twentieth century 1914-1991. London: Michael Joseph, 1994.

IPSOS-MORI. Robo-rights: Utopian dream or rise of the machines? London: Office of Science and Innovation's Horizon Scanning Centre, United Kingdom Government, 2006.

JENSON, Jane. Getting to sewers and sanitation: doing public health within nineteenth-century Britain's citizenship regimes. Politics and Society, 2008, vol. 36, n 4, p. 532-556.

JONES, Leroy; JAMMAL, Yahya; GÖKGÜR, Nilgün \& KIKERI, Sunita. Doing privatization right. Public Policy for the Private Sector, $n^{\circ}$. 319, Washington DC: World Bank, 2008. <http://rru.worldbank.org/documents/publicpolicy journal/319Doing_privatization_right.pdf>, (Consultado en noviembre de 2009).

KING, Desmond S. New Right ideology, welfare state form, and citizenship: a comment on Conservative capitalism. Comparative Studies in Society and History, 1988, vol. 30, n 4, p. 792799.

KOUVÉLAKIS, Stathis. The Marxian critique of citizenship: for a rereading of "On the Jewish question". South Atlantic Quarterly, 2005, vol. $104, n^{\circ} 4$, p. $707-721$.

KROEN, Sheryl. A political history of the consumer. The Historical Journal, 2004, vol. 47, $\mathrm{n}^{\circ} 3$, p. 709-736.

KUECKER, Glen David. Fighting for the forests: grassroots resistance to mining in Northern Ecuador. Latin American Perspectives, 2007, vol. $34, \mathrm{n}^{\circ} 2$, p. 94-107.

LABRE, Jacques. Human Rights and Access to Drinking Water and Sanitation. Contribution to OHCHR Consultation (Human Rights Council's decision 2/104). Paris: Suez Environment, 2007. Disponible <http://www2.ohchr.org/english/issues/water/con tributions/PrivateSector/Suez.pdf>. (Consultado en noviembre de 2009).

LEYS, Colin. Market-driven politics: neoliberal democracy and the public interest. London: Verso, 2001.

LISTER, Michael \& PIA, Emily. Citizenship in contemporary Europe. Edimburgh: Edinburgh University Press, 2008.

LOJKINE, Jean. El marxismo, el estado y la cuestión urbana. México: Siglo XXI, 1979.

MCDONALD, David A. \& RUITERS, Greg. The age of commodity: water privatization in Southern Africa. London / Sterling, VA.: Earthscan, 2004.

MALINGA, Joseph. Water supply at Katine health centre turned off. The Guardian, 23 de noviembre de 2009. <http://www.guardian.co.uk/katine/2009/nov/23/ health-centre-water-disconnected>. (Consultado en noviembre de 2009).

MARÍN, Juan Carlos. Los hechos armados. Argentina 1973-1976. La acumulación primitiva del genocidio. Buenos Aires: Ediciones PICASO/La Rosa Blindada, 1996.

MARSHALL, Thomas H. Citizenship and social class. In MARSHALL, Th. H. Sociology at the 
Crossroads and Other Essays. London: Heinemann, 1963, p. 67-127.

MEAD, Lawrence M. Beyond Entitlement: the Social Obligations of Citizenship. New York: Free Press, 1986.

MELOSI, Martin V. The sanitary city: urban infrastructure in America from colonial times to the present (creating the North American landscape). Baltimore: John Hopkins University Press, 2000.

MORRISON, Trevor W. Suspensions and the extrajudicial constitution. Columbia Law Review, 2007, vol. $107, n^{\circ} 7$, p. 1533-1616.

MUKHOPADHYAY, Asok Kumar. The politics of London water. The London Journal, 1975, vol. 1, $\mathrm{n}^{\circ} 2$, p. 207-226.

MULREANY, John P.; CALIKOGLU, Sule; RUIZ, Sonia \& SAPSIN, Jason W. Water privatization and public health in Latin America. Pan American Journal of Public Health, 2006, vol. 19, n 1, p. 23-32.

MURRAY, Charles. Loosing ground. New York: Basic Books, 1984.

NELSON, Gerald C. \& ROBERTSON, Richard D. Green gold or green wash: environmental consequences of biofuels in the developing world. Review of Agricultural Economics, 2008, vol. 30, $\mathrm{n}^{\circ} 3$, p. 517-529.

NEWBY, Howard. Citizenship in a green world: global commons and human stewardship. In BULMER, M. \& REES, A.M. Citizenship Today. The Contemporary relevance of T. H. Marshall. London: University College Press, 1996, p. 209221.

NEWELL, Peter. Bio-hegemony: the political economy of agricultural biotechnology in Argentina. Journal of Latin American Studies, 2009, vol. 41, n 1, p. 27-57.

NORTH, Douglass C. \& THOMAS, Robert Paul. The rise of the Western world: a new economic history. Cambridge: Cambridge University
Press, 1973.

O'DONNELL, Guillermo. Delegative democracy. Journal of Democracy, 1994, vol. 5, n 1, p. 5569

OGLE, Maureen. Water supply, waste disposal, and the culture of privatism in the midnineteenth-century American city. Journal of Urban History, 1999, vol. 25, n 3, p. 321-347.

ONU - ORGANIZACIÓN DE LAS NACIONES UNIDAS. "Declaración". Conferencia de las Naciones Unidas sobre el Medio Ambiente y el Desarrollo. Río de Janeiro: ONU, 1992

ORDÓÑEZ CIFUENTES, José Emilio Rolando (Ed.). El derecho a la lengua de los pueblos indígenas. México DF: Instituto de Investigaciones Jurídicas, Universidad Nacional Autónoma de México, 2003

PEZON, Christelle. Le Service d'eau potable en France de 1850 à 1995. Paris: CNAM, Presses du CEREM, 2000.

PICCIOTTO, Robert. Putting institutional economics to work: from participation to governance. In: CLAGUE, Ch. K. (ed.). Institutions and economic development: Growth and governance in less-developed and post-socialist countries. Baltimore / London: John Hopkins University Press, 1997 , p. 343-367.

POLANYI, Karl. The Great Transformation: the political and economic origins of our time. Boston: Beacon Press, 1957.

PORTALES, Felipe. Chile: una democracia tutelada. Santiago de Chile: Editorial Sudamericana Chilena, 2000.

PRETECEILLE, Edmond. La planification urbaine. Les contradictions de l'urbanisation capitaliste. Economie et Politique, 1974, n 236, p. 94-114.

ROBBINS, Bruce (Ed.). The phantom public sphere. Minneapolis: University of Minnesota Press, 1995.

ROBERTS, Bryan R. The making of citizens. Cities of peasants revisited. London: Arnold, 1995. 
ROKKAN, Stein. Citizens, Elections, Parties. Approaches to the Comparative Study of the Processes of Development. Colchester, UK: European Consortium for Political Research (ECPR), 2009.

ROZE, Jorge. Chaco y Corrientes - Informe del Estudio de Caso de Argentina, Proyecto PRINWASS. Oxford: Universidad de Oxford, 2003.

RULLI, Jorge Eduardo. Pueblos fumigados. Los efectos de los plaguicidas en las regiones sojeras. Buenos Aires: Del Nuevo Extremo, 2009.

SALZMAN, James. Thirst: a short history of drinking water. Duke Law School Legal Studies, Research Paper Series, Research Paper $n^{\circ}$ 92, 2005.

SANTOS, Carlos; VILLARREAL, Alberto. Uruguay: direct democracy in defense of the right to water. In BALANYÁ, B., BRENNAN, B., HOEDEMAN, O. KISHIMOTO, S. y TERHORST, P. Reclaiming public water. Achievements, struggles and visions from around the world. London: Transnational Institute and Corporate Europe Observatory, 2005, p. 173-179.

SOLANES, Miguel. América Latina: ¿sin regulación ni competencia? Impactos sobre la gobernabilidad del agua y sus servicios. Santiago de Chile: Comisión Económica para América Latina y el Caribe (CEPAL), 2002. Disponible en <http://prinwass.ncl.ac.uk/PDFs/Solanes.PDF>. (Consultado el 18 de junio de 2011).

SOPER, Kate \& TRENTMANN, Frank (Eds.). Citizenship and consumption. Houndmills / Basingstoke / New York: Palgrave-Macmillan, 2008.

SOUSA, Jessé. A construção social da subcidadanía. Para uma sociologia política da modernidade periférica. Belo Horizonte: Editora UFMG / Río de Janeiro: IUPERJ, 2006.

STEENBERGEN, Bart von. Towards a global ecological citizen. In STEENBERGEN, B. von. The condition of citizenship. London: Thousand
Oaks, 1994, p. 141-152.

SVAMPA, Maristella. La sociedad excluyente. La Argentina bajo el signo del neoliberalismo. Buenos Aires: Taurus, 2005.

SWYNGEDOUW, Erik; KAÏKA, Maria \& CASTRO, J. Esteban. Urban water: a political-ecology perspective. Built Environment, 2002, vol. 28, $\mathrm{n}^{\circ} 2$, p. 124-137.

SWYNGEDOUW, Erik. Dispossessing H2O: the Contested Terrain of Water Privatization. Capitalism Nature Socialism, 2005, vol. 16, $\mathrm{n}^{\circ} 1, \mathrm{p}$. 81 - 98

THE ECONOMIST. Regulation of the supply of water, 1850, nº. 334, p. 62.

THEORY AND SOCIETY, Special issue on recasting citizenship. Theory and Society, 1997, vol. $26, n^{\circ} 4$.

TILLY, Charles. Changing forms of inequality. Sociological Theory, 2003, vol. 21, $n^{\circ} 1$, p. 3136.

TOPALOV, Christian. La urbanización capitalista. México DF: Edicol, 1979.

TORREGROSA, María Luisa; SAAVEDRA, Fernando; PADILLA, Esther; QUIÑONES, Alice; KLOSTER, Karina; Cosío, Gabriel y LENIN, Christian. Aguascalientes - Informe del Estudio de Caso México, Proyecto PRINWASS. Oxford: Universidad de Oxford, 2003.

TORRES RIVAS, Edelberto. Democracias de baja intensidad. Pensamiento Iberoamericano, 1989, no 14, p. 221-230.

VEOLIA. The right to water: from concept to effective implementation. (Respuesta a la consulta de la Oficina del Alto Comisionado de las Naciones Unidas para los Derechos Humanos-ACNUDH). Paris: Veolia, 2007. Disponible en <http://www2.ohchr.org/english/issues/water/con tributions/PrivateSector/Veolia.pdf>. (Consultado en noviembre de 2009).

UNITED NATIONS EDUCATIONAL, SCIENTIFIC AND CULTURAL ORGANIZATION - 


\section{UNESCO, WORLD WATER ASSESSMENT} PROGRAMME. Water, a Shared Responsibility. The United Nations World Water Report 2. Paris I New York: UNESCO \& Berghahn Books, 2006. URKIDI AZKARRAGA, Leire. Environmental justice and the politics of scale in Latin American social movements against gold mining. The cases of Pascua-Lama in Chile and Marlin in Guatemala. Tesis de Doctorado en Ciencias del Ambiente, Barcelona: Universidad Autónoma de Barcelona, 2010.

VAN DIJCK, Pitou \& DEN HAAK, Simon. Troublesome Construction. IIRSA and Public-Private Partnerships in Road Infrastructure. Amsterdam: Center for Latin American Studies and Documentation (CEDLA), 2007.

WAKSMAN, Guillermo. Uruguay: Consagración de la democracia tutelada. Nueva Sociedad, 1989, no 102, p. 13-19.

WARD, Colin. Reflected in water. A crisis of social responsibility. London: Cassell.

WATER AND SANITATION PROGRAM (WSP) \& PUBLIC PRIVATE INFRASTRUCTURE ADVISORY FACILITY (PPIAF). New designs for water and sanitation transactions. Making private sector participation work for the poor. Washington, DC: World Bank, 2002.

YAMIN, Alicia Ely. Derechos económicos, sociales y culturales en América Latina. Del invento a la herramienta. México DF: Asociación pro Derechos Humanos (APRODEH), Centro Internacional de Investigaciones para el Desarrollo (IDRC) y Plaza y Valdés, 2006.

YARROW, George; APPLEYARD, Tony; DECKER, Christopher \& KEYWORTH, Timothy. Competition in the provision of water services. Oxford: Regulatory Policy Institute, 2008. <http://www.rpieurope.org/Research/Report\%20 on $\% 20$ Competition $\% 20$ in $\% 20$ Water\%20Service s.pdf>. (Consultado en noviembre de 2009).

\section{Cita del artículo}

CASTRO, J. Esteban. El proceso de democratización de la gestión de servicios públicos esenciales de agua y saneamiento. Hábitat y sociedad, 2011, nº 2, p. 4985. <www.habitatysociedad.us.es>.

http://dx.doi.org/10.12795/HabitatySociedad.2011.i2.04 